Article

\title{
Application of AMOGWO in Multi-Objective Optimal Allocation of Water Resources in Handan, China
}

\author{
Su Li ${ }^{1,2}$, Zhihong Yan ${ }^{1,2, * \mathbb{D}}$, Jinxia Sha ${ }^{3, * \mathbb{D}}$, Jing Gao ${ }^{4}$, Bingqing Han ${ }^{5}$, Bin Liu ${ }^{1,2} \mathbb{D}$, Dan Xu ${ }^{1,2}$, Yifan Chang ${ }^{1}$, \\ Yuhang Han ${ }^{1} \mathbb{D}$, Zhiheng $\mathrm{Xu}^{1}$ and Bolun Sun ${ }^{1}$
}

1 School of Water Conservancy and Hydroelectric Power, Hebei University of Engineering, Handan 056021, China; susan627530@163.com (S.L.); liubin820104@163.com (B.L.); xudan930328@163.com (D.X.); 13223022656@163.com (Y.C.); han15231439574@163.com (Y.H.); xzh201603@163.com (Z.X.); S13151091833@163.com (B.S.)

2 Hebei Key Laboratory of Intelligent Water Conservancy, Hebei University of Engineering, Handan 056001, China

3 School of Earth Science and Engineering, Hebei University of Engineering, Handan 056021, China

4 Water Conservancy Management of Handan City, Handan 056021, China; wljgood@163.com

5 Runze Water Co., Ltd. of Fengfeng Handan, Handan 056038, China; cindy-851224@163.com

* Correspondence: yanzhihong0526@126.com (Z.Y.); shajinxia@163.com (J.S.); Tel.: +86-31-0312-3702 (Z.Y. \& J.S.)

Citation: Li, S.; Yan, Z.; Sha, J.; Gao, J.; Han, B.; Liu, B.; Xu, D.; Chang, Y.; Han, Y.; Xu, Z.; et al. Application of AMOGWO in Multi-Objective Optimal Allocation of Water Resources in Handan, China. Water 2022, 14, 63. https://doi.org/ $10.3390 / w 14010063$

Academic Editor: Antonio Lo Porto

Received: 5 November 2021

Accepted: 27 December 2021

Published: 29 December 2021

Publisher's Note: MDPI stays neutral with regard to jurisdictional claims in published maps and institutional affiliations.

Copyright: (C) 2021 by the authors. Licensee MDPI, Basel, Switzerland. This article is an open access article distributed under the terms and conditions of the Creative Commons Attribution (CC BY) license (https:// creativecommons.org/licenses/by/ $4.0 /)$.

\begin{abstract}
The reasonable allocation of water resources using different optimization technologies has received extensive attention. However, not all optimization algorithms are suitable for solving this problem because of its complexity. In this study, we applied an ameliorative multi-objective gray wolf optimizer (AMOGWO) to the problem. For AMOGWO, which is based on the multi-objective gray wolf optimizer, we improved the distance control parameter calculation method, added crowding degree for the archive, and optimized the selection mechanism for leader wolves. Subsequently, AMOGWO was used to solve the multi-objective optimal allocation of water resources in Handan, China, for 2035, with the maximum economic benefit and minimum social water shortage used as objective functions. The optimal results obtained indicate a total water demand in Handan of $2740.43 \times 10^{6} \mathrm{~m}^{3}$, total water distribution of $2442.23 \times 10^{6} \mathrm{~m}^{3}$, and water shortage of $298.20 \times 10^{6} \mathrm{~m}^{3}$, which is consistent with the principles of water resource utilization in Handan. Furthermore, comparison results indicate that AMOGWO has substantially enhanced convergence rates and precision compared to the non-dominated sorting genetic algorithm II and the multi-objective particle swarm optimization algorithm, demonstrating relatively high reliability and applicability. This study thus provides a new method for solving the multi-objective optimal allocation of water resources.
\end{abstract}

Keywords: multi-objective optimization; water resources; optimal allocation; AMOGWO; Handan

\section{Introduction}

Global water demand is continuously increasing concomitant with the rapid growth and development of societies and economies [1]. The shortage of water resources has become a key problem hindering economic and social development [2-4]. In particular, China's total water resources account for $6 \%$ of the total global water resources. However, because of its large population, its water resources per capita is approximately one-fourth of the world average [5]. Moreover, the shortage of water resources is further exacerbated by the incompatibility of the spatial and temporal distributions of water resources with the water demand in some areas, the rapid development of industries, and an increasingly critical water pollution problem [6]. Therefore, it is necessary to optimize the allocation of water resources, transfer water resources from low-value to high-value use, and improve the utilization efficiency of water resources to solve water shortages.

The optimal allocation of water resources is an important method to realize the effective and fair distribution of water resources in different regions and among water users by 
applying various engineering and non-engineering measures to achieve the sustainable utilization of water resources [7]. It is considered a multi-objective optimization problem in which the objectives conflict with each other, making it difficult to optimize all objectives simultaneously.

There are two main approaches for handling multiple objectives: a priori and a posteriori $[8,9]$. The a priori approach first normalizes all objectives and then transforms the multiple objectives into a single objective using the weighting method, objective programming method, or constraint method. Finally, the single objective is solved using an existing mature single objective optimization method [10]. The optimal solution obtained by this method often converges to the local optimal solution rather than the global optimal solution [11,12]. The a posteriori method maintains the multiple objectives formulation, and obtains a set of solutions across a range of design parameters and operating conditions. Decision-makers then need to choose the most suitable solution set according to their preferences.

For the multi-objective, multi-variable, and high-dimensional optimal allocation model of water resources, the traditional optimization algorithm is not satisfactory in terms of convergence, computational efficiency, and parameter sensitivity. Since 1984, meta-heuristic optimization algorithms have become increasingly popular in engineering applications because of their simple concept, easy implementation, gradient information independence, and the fact that they can bypass local optimization. Consequently, numerous researchers have been dedicated to using meta-heuristic algorithms to solve multi-objective optimal allocation problems [13].

Meta-heuristic algorithms can be classified into three categories: evolution-based, physics-based, and swarm-based. Multi-objective evolutionary algorithms [14] are an improvement on single objective genetic algorithms that are inspired by the concepts of natural evolution $[15,16]$. They include the strength-pareto evolutionary algorithm (SPEA) [17], the non-dominated sorting genetic algorithm (NSGA) [18], and NSGA-II [19]. Since Rosenberg [20] proposed the use of an evolutionary search method to solve multiobjective optimization problems in 1967, the evolutionary multi-objective optimization algorithm (EMO) has attracted the attention of various researchers [17,21-25].

The physics-based optimization algorithms imitate physical rules, that is, the movements of the search agents are based on weights, gravitational force, electromagnetic force, etc. The most representative of these algorithms are the gravitational search algorithm [26], gravitational local search algorithm [27], black hole algorithm [28], ray optimization algorithm [29], galaxy-based search algorithm (GbSA) [30], and curved space optimization (CSO) [31] algorithm.

The swarm-based multi-objective optimization algorithms typically adopt the Pareto method and combine with a swarm intelligence optimization algorithm based on biological intelligence or physical phenomena, such as particle swarm optimization (PSO) [32], ant colony optimization (ACO) [33], artificial fish swarm algorithm (AFSA) [34], fruit fly optimization algorithm (FOA) [35], and whale optimization algorithm (WOA) [36]. The swarm-based algorithms have been proved to be very competitive with evolution-based and physics-based algorithms, because of their fewer operators compared to evolutionary approaches and implementation ease [37]. The swarm-based algorithms have been used to solve various real problems [38,39], and have also been successfully applied for the optimal allocation of water resources [40-43].

According to the no free lunch (NFL) theorem, no single optimization algorithm can solve all optimization problems [44]. A specific meta-heuristic algorithm may show very promising results for one set of problems but cannot guarantee a similar performance on another set of problems. Inspired by the predation behavior of gray wolves, in 2014, Mirjalili et al. [45] proposed a new nature-inspired heuristic optimization algorithm called the gray wolf optimization (GWO) algorithm. GWO simulates the predation behavior of the gray wolf group and achieves optimization based on the mechanism of wolf group cooperation. The GWO algorithm has the characteristics of a simple structure, 
few parameters to adjust, and ease of implementation. Among them, there are adaptive convergence factors and information feedback mechanisms that can achieve a balance between local optimization and global search. Therefore, the GWO algorithm has good problem-solving accuracy and convergence speed. GWO is widely used in engineering design [46,47], path planning [48,49], electric load forecasting [50], building energy optimization [51], feature subset selection [52], image processing [53-55], and multiple hydropower reservoir operations [56,57].

However, GWO easily falls into local optimum in multimodal optimization problems [46], and there are some disadvantages in applying the GWO algorithm directly to multi-objective optimization problems. First, the fitness value of GWO cannot be simply expressed by a function value, and it is difficult to choose the $\alpha, \beta$, and $\delta$ wolves directly from the group by using the Pareto dominance relationship; further, the exploration ability is insufficient. Second, the algorithm uses the leading wolf to guide the wolves to search, and ignores the non-dominated solution near the leading wolf, resulting in its weak global search ability. Third, in the updating of wolf location, the leading wolf effect is much greater than the random factor, resulting in strong dependence on the initial value of the leading wolf and lack of its own adjustment ability.

In 2016, Mirjalili et al. [58] subsequently proposed an improved algorithm called the multi-objective gray wolf optimizer (MOGWO), which is based on GWO. However, it does not improve the drawback of small search range and fast convergence in the early stage, and large search range and low accuracy in the later stage [59]. In this paper, the ameliorative multi-objective gray wolf optimizer (AMOGWO), which is based on MOGWO, is proposed to solve the multi-objective optimization of water resources. In AMOGWO, the calculation method of the distance control parameter $a$ is improved; further, a crowding degree is added for the archive to make the number of solutions in the archive not exceed the upper limit and maintain the population diversity; in addition, the selection mechanism for leader wolves is improved to enhance the exploration ability of the algorithm. The contributions of this study are the evaluation of the effectiveness of AMOGWO and provision of a new method for solving the problem of multi-objective water resources optimal allocation.

\section{Materials and Methods}

\subsection{Grey Wolf Optimization (GWO) Algorithm}

Grey wolves belong to the Canidae family and are considered apex predators. They have a very strict social hierarchy, which is generally divided into four levels, as shown in Figure 1. The first layer of the pyramid comprises the leader in the population, called $\alpha$, which is mainly responsible for the management of all the wolves. The second layer is called $\beta$, and comprises subordinate wolves that assist the $\alpha$ in decision-making or other pack activities. The third layer is $\delta$, it comprises wolves that submit to decisions and orders from $\alpha$ and $\beta$, but they dominate the wolves in the lowest layer. At the bottom of the pyramid is $\omega$, which comprises wolves that are mainly responsible for the balance of internal relations of the population.

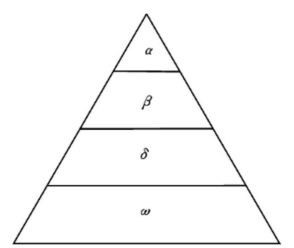

Figure 1. Social hierarchy of gray wolves.

GWO is designed based on the social leadership and hunting behavior of gray wolves [46]. In this algorithm, the $\alpha, \beta$, and $\delta$ wolves represent the fittest, second best, and third best solutions, respectively, and the remaining candidate solutions are assumed to be 
$\omega$ wolves. The $\omega$ wolves follow the $\alpha, \beta$, and $\delta$ wolves in searching for the global optimum. The gray wolf updates its position based on the distance between itself and the prey:

$$
\begin{gathered}
\vec{X}(t+1)=\vec{X}_{p}(t)-\vec{A} \cdot \vec{D}, \\
\vec{D}=\left|\vec{C} \cdot \vec{X}_{p}(t)-\vec{X}(t)\right| \\
\vec{A}=2 \vec{a} \cdot \overrightarrow{r_{1}}-\vec{a} \\
\vec{C}=2 \cdot \overrightarrow{r_{2}},
\end{gathered}
$$

where $t$ is the current iteration, $\vec{X}_{p}$ is the position vector of the prey, $\vec{X}$ is the position vector of a grey wolf, $\vec{A}$ and $\vec{C}$ are coefficient vectors, $\vec{D}$ is the distance between the grey wolf and the prey, $\vec{a}$ linearly decreases from " 2 " to " 0 " over the course of iterations, and $\overrightarrow{r_{1}}$ and $\overrightarrow{r_{2}}$ are random vectors in $[0,1]$.

In the optimization process, the $\alpha, \beta$, and $\delta$ wolves need to determine the location information of $\vec{X}_{p}(t)$, which is unknown. The location information of each $\omega$ grey wolf can be updated using the following equations:

$$
\begin{gathered}
\vec{D}_{\alpha}=\left|\overrightarrow{C_{1}} \cdot \vec{X}_{\alpha}-\vec{X}(t)\right|, \\
\vec{D}_{\beta}=\left|\overrightarrow{C_{2}} \cdot \vec{X}_{\beta}-\vec{X}(t)\right|, \\
\vec{D}_{\delta}=\left|\overrightarrow{C_{3}} \cdot \vec{X}_{\delta}-\vec{X}(t)\right|, \\
\vec{X}_{1}(t+1)=\vec{X}_{\alpha}-\overrightarrow{A_{1}} \cdot \vec{D}_{\alpha}, \\
\vec{X}_{2}(t+1)=\vec{X}_{\beta}-\overrightarrow{A_{2}} \cdot \vec{D}_{\beta}, \\
\vec{X}_{3}(t+1)=\vec{X}_{\delta}-\overrightarrow{A_{3}} \cdot \vec{D}_{\delta}, \\
\vec{X}(t+1)=\frac{\vec{X}_{1}+\vec{X}_{2}+\vec{X}_{3}}{3} .
\end{gathered}
$$

\subsection{Ameliorative Multi-Objective Grey Wolf Optimizer (AMOGWO)}

The MOGWO is based on the GWO algorithm, with two new components incorporated for performing optimization. The first component is an archive that stores the obtained non-dominated Pareto optimal solutions, and the second component is a leader selection strategy that assists in choosing $\alpha, \beta$, and $\delta$ wolves from the archive as leaders in the hunting process [59].

To make the MOGWO algorithm have a higher exploration ability in the early stage and strong exploitation ability in the later stage, the algorithm is improved as follows.

\subsubsection{Improvement of Distance Control Parameters}

According to the GWO, the coefficient vector $\vec{A}$ can balance local search and global search. If $|\vec{A}| \geq 1$, the search range will increase, which is conducive to global search. If $|\vec{A}|<1$, the search accuracy is strengthened, which is conducive to local search. In Equation (3), $\vec{r}_{1}$ is a random number in the range [0,1], hence the parameter $\vec{a}$ determines the size of $\vec{A}$ and plays a key role in the exploration and exploitation. The larger the value 
of $\vec{a}$, the stronger the exploration ability of the algorithm; the smaller the $\vec{a}$ value, the higher the search accuracy. In the GWO algorithm, $a=2\left(1-t / t_{\max }\right)$, where $t_{\max }$ is the maximum number of iterations. In this study, a distance control parameter calculation method based on a circular formula is proposed; specifically, $a=2 \times \sqrt{1-\left(t / t_{\max }\right)^{2}}$. The variation of $a$ with the number of iterations is shown in Figure 2.

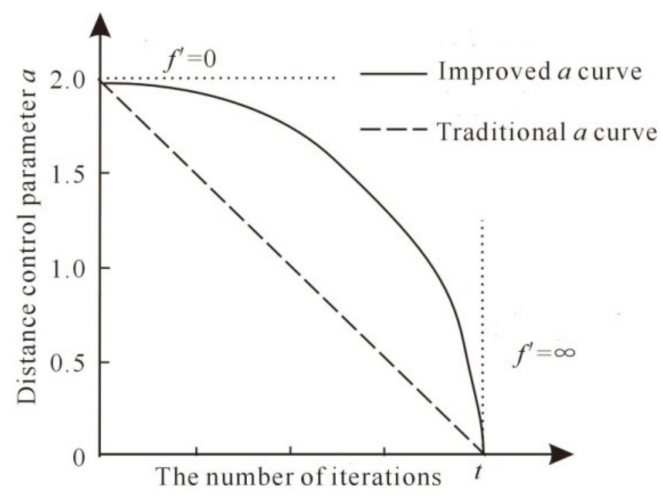

Figure 2. Variation of distance control parameter $a$ with the number of iterations.

\subsubsection{Crowding Degree Added for the Archive}

The archive is a simple storage unit with a maximum number and uses an archive controller to control the entry and omission of the obtained non-dominated Pareto optimal solutions from the archive. In the iteration process, if an individual in the archive dominates the new solution generated, the new solution is not be added to the archive. Conversely, if the new solution dominates one or more individuals in the archive, the new solution should replace the individual dominated. If the new solution is independent of all individuals in the archive, the new solution should be added to the archive.

In the updating process, the number of individuals in the archive will increase. However, the archive has an upper limit. Thus, to make the number of solutions in the archive not exceed the upper limit and maintain the population diversity, the MOGWO uses the grid mechanism. However, in this paper, the population in the archive is limited according to the crowding degree of the solutions in NSGA-II. The calculation process is as follows.

First, calculate the objective function $f\left(f_{1}, f_{2}, \cdots, f_{n},\right)$ of each resident in the archive, and determine the extreme values $f_{i \max }$ and $f_{i \min }$ of each objective function. Then, calculate the crowding degree $D_{c}$ of each resident. Each solution has the attribute of crowding degree in the whole solution space:

$$
D_{c}(j)=\sum_{i=1}^{M} \frac{f_{i}(j+1)-f_{i}(j-1)}{f_{i \max }-f_{\text {imin }}}
$$

where $f_{i}(j+1)$ and $f_{i}(j-1)$ represent the value of the $i$ objective function of the two adjacent individuals of $j$.

Finally, when the number of individuals in the archive exceeds the upper limit, the individuals with higher crowding degree, that is, the individuals with smaller $D_{c}$, are preferentially selected and eliminated from the archive to maintain the upper limit.

\subsubsection{Improvement of the Selection Strategy for Leader Wolves}

In the MOGWO, a leader selection strategy is used to select the $\alpha, \beta$, and $\delta$ wolves. Specifically, it uses the roulette-wheel method $P_{i}=c / N_{i}$, where $P_{i}$ is the probability of each segment, $c$ is a constant number greater than one, and $N_{i}$ is the number of obtained Pareto optimal solutions in the $i$-th segment, to select the least crowded segments of the archive and offer one of its non-dominated solutions as $\alpha, \beta$, and $\delta$ wolves. Moreover, it is necessary to exclude $\alpha$ and $\beta$ from the archive temporarily when selecting the $\beta$ and $\delta$ wolves to avoid selecting the same leader. 
In this paper, the selection mechanism of $\alpha, \beta$, and $\delta$ wolves is redefined. The current optimal solution is stored in the archive, and individuals are directly selected from the archive as the leader wolves. The $\alpha, \beta$, and $\delta$ wolves are selected using the method $P_{j}=\left(D_{c}(j)\right)^{C}$, where $C$ is a constant number greater than one. The smaller the $D_{c}$ value is, the lower is the probability of being selected.

\section{Case Study}

\subsection{Background of the Study Area}

Handan is located in the southern part of Hebei Province, China, and has a history of 3100 years, as shown in Figure 3. The population of the city is approximately 9.414 million. In addition, the area of this region is $12,047 \mathrm{~km}^{2}$, in which the mountainous and plain regions cover areas of $4460 \mathrm{~km}^{2}$ and $7587 \mathrm{~km}^{2}$, respectively. Handan has a temperate, semi-humid, and arid continental monsoon climate. The annual average temperature is approximately $12.5-14.2{ }^{\circ} \mathrm{C}$, and the annual average precipitation is $537.6 \mathrm{~mm}$, which is concentrated from June to September. The main rivers in the territory are the Fuyang River, Zhanghe River, Weihe River, Minghe River, LiuLei River, Laozhang River, Laosha River, and Majia River. The per capita water resource in Handan is $118 \mathrm{~m}^{3}$, which is a resource-based water shortage area. Moreover, with the rapid economic development, the shortage of water resources has become the main factor that restricts and limits sustainable economic development and ensures the safety of water use.

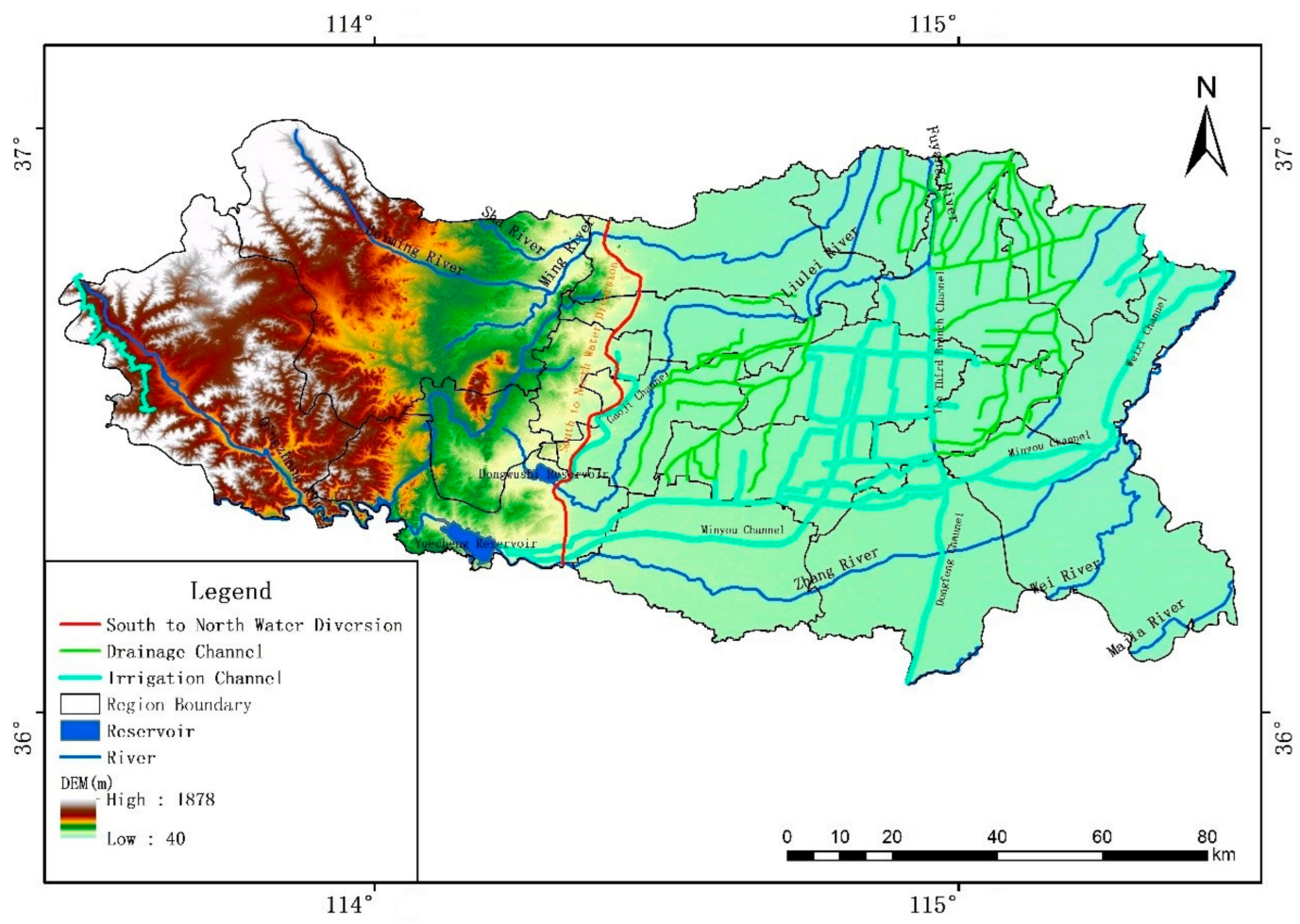

Figure 3. Map of the administrative division and water supply system in Handan.

The background conditions of water resources in Handan are weak, there are many people and limited water. Further, the temporal and spatial distribution of water resources is uneven, and it does not match the layout of productivity. With the rapid development of the social economy and the impact of global climate change, the degree of development and utilization of water resources is increasing, resulting in an imbalance between the supply and demand of water resources in the region. Simultaneously, with the decrease in water from the upstream, a large amount of groundwater is being overexploited, and the groundwater level continues to decline, forming multiple groundwater depression areas, resulting in land subsidence and frequent geological disasters. In Handan, the 
problem of water shortage is serious, the allocation of water resources is unreasonable, and the consumption of water in industry and agriculture is inefficient. Consequently, the adaptation and implementation of an optimal allocation technology that can scientifically and reasonably allocate the water supply in various industries and the society, realize the optimal dispatching and rational development of multiple water sources and users, and ensure the sustainable utilization of water resources and the sustainable development of the economy and society, has become a major problem to be solved because of the existing water resources and water environment conditions in this region.

\subsection{Water Allocation System}

Based on the characteristics of the Handan water resources system and the administrative divisions, the region is divided into 16 subregions: Shexian, Wuan, Fengfeng, Feixiang, Handan City, Yongnian, Guangping, Cheng'an, Guantao, Daming, Cixian, Weixian, Linzhang, Qiuxian, Quzhou, and Jize. Five types of water users and water sources were generalized in the optimal allocation of water resources in Handan.

The water users in Handan are divided into five categories: domestic, primary sector, secondary sector, tertiary sector, and ecological. Specifically, the primary sector covers the agriculture, forestry, livestock farming, and fisheries, the secondary sector comprises industries that produce finished and usable products and construction industries, and the tertiary sector includes catering and services.

The five water sources are local surface water, groundwater, reservoir water, externally transferred water, and recycled water. The local surface water, groundwater, and recycled water are independent water sources, whereas the reservoir water and externally transferred water are public water sources. The reservoir water includes the Yuecheng Reservoir and Dongwushi Reservoir, which supply subregions such as Feixiang, Handan City, Yongniant, Guangping, Cheng'an, Guantao, Daming, Cixian, Weixian, Linzhang, Qiuxian, Quzhou, and Jize with primary sector users, secondary sector users, and ecological users. The externally transferred water includes Yellow River-transferred water, Weihe River-transferred water, and South-North-transferred water. Thirteen subregions are supplied by the South-North-transferred water: Handan City, Feixiang, Yongnian, Guangping, Cheng'an, Guantao, Daming, Cixian, Weixian, Linzhang, Qiuxian, Quzhou, and Jize. The water users in this case include urban and rural domestic users, secondary sector users, and tertiary sector users. The Yellow River Diversion supplies subregions such as Feixiang, Guangping, Guantao, Daming, Weixian, Qiuxian, Quzhou, and Jize, and water users include primary sector users, secondary sector users, and ecological users. Three subregions are supplied by Weihe water-Guantao, Daming, and Weixian-which also have primary sector users.

\subsection{Optimal Water Resource Allocation Model}

The optimal water resource allocation model is established by taking the social and economic benefits as the objective functions and combining them with the corresponding constraint conditions.

\subsubsection{Objective Functions}

\section{Social Benefits Target}

The social benefit is usually represented indirectly by the minimum regional water shortage.

$$
\max f_{1}(x)=-\min \left\{\sum_{k=1}^{K} \sum_{j=1}^{J(k)}\left[D_{j}^{k}-\left(\sum_{i=1}^{I(k)} x_{i j}^{k}+\sum_{c=1}^{M} x_{c j}^{k}\right)\right]\right\}
$$


Economic Benefit Target

The economic benefits target is characterized by the maximum net economic benefit yielded by the regional water supply.

$$
\max f_{2}(x)=\max \left\{\sum_{k=1}^{K} \sum_{j=1}^{J(k)}\left[\sum_{i=1}^{I(k)}\left(b_{i j}^{k}-c_{i j}^{k}\right) x_{i j}^{k} \alpha_{i}^{k}+\sum_{c=1}^{M}\left(b_{c j}^{k}-c_{c j}^{k}\right) x_{c j}^{k} \alpha_{c}^{k}\right] \lambda_{j}^{k}\right\},
$$

where $D_{j}^{k}$ is the water demand of user $j$ in subregion $k\left(\times 106 \mathrm{~m}^{3}\right) ; x_{i j}^{k}$ and $x_{c j}^{k}$ are the water supplies from independent source $i$ and public source $c$ to user $j$ in subregion $k\left(\times 106 \mathrm{~m}^{3}\right)$, respectively; $b_{i j}^{k}$ and $b_{c j}^{k}$ are the coefficients of efficiency per unit water supply from independent source $i$ and public source $c$ to user $j$ in subregion $k\left(\mathrm{CNY} / \mathrm{m}^{3}\right)$, respectively; $c_{i j}^{k}$ and $c_{c j}^{k}$ are the coefficients of cost per unit water supply from independent source $i$ and public source $c$ to user $j$ in subregion $k\left(\mathrm{CNY} / \mathrm{m}^{3}\right)$, respectively; $\alpha_{i}^{k}$ and $\alpha_{c}^{k}$ are the coefficients of water supply sequence from independent source $i$ and public source $c$ to user $j$ in subregion $k$, respectively; $K(K=16)$ is the total number of subregions; $I(k)(I(k)=3)$ is the number of the independent sources in subregion $k ; J(k)(J(k)=5)$ is the number of users in subregion $k ; M(M=2)$ is the total number of public sources; and $\lambda_{j}^{k}$ is the water supply fairness coefficient of user $j$ in subregion $k$.

3.3.2. Constraint Conditions

Water Supply Capacity Constraints

Independent water resource

$$
\sum_{j=1}^{J(k)} x_{i j}^{k} \leq W_{i}^{k}
$$

Public water resource

$$
\begin{aligned}
& \sum_{j=1}^{J(k)} x_{c j}^{k} \leq W_{c}^{k} \\
& \sum_{k=1}^{K} W_{c}^{k} \leq W_{c}
\end{aligned}
$$

Here, $W_{c}^{k}$ and $W_{i}^{k}$ are the available water supplies by public source $c$ and independent source $i$ in subregion $k$, respectively, and $W_{c}$ is the available water supplies by public source $c$.

Water Delivery Capacity Constraints

$$
\begin{aligned}
& \text { Independent water resource } \\
& \qquad x_{i j}^{k} \leq Q_{i}^{k}
\end{aligned}
$$

Public water resource

$$
W_{c}^{k} \leq Q_{c}^{k}
$$

Here, $Q_{i}^{k}$ and $Q_{c}^{k}$ are the maximum water delivery capacities of the independent source $i$ and public source $c$ in the subregion $k$, respectively.

Users' Water Demand Constraints

$$
D_{j \min }^{k} \leq \sum_{i-1}^{I(k)} x_{i j}^{k}+\sum_{c=1}^{M} x_{c j}^{k} \leq D_{j \max }^{k}
$$

Here, $D_{j \text { min }}^{k}$ and $D_{\text {jmax }}^{k}$ are the minimum and maximum water demands of the user $j$ in the subregion $k$, respectively. 
Non-Negative Variables

$$
\begin{aligned}
& x_{i j}^{k} \geq 0 \\
& x_{c j}^{k} \geq 0
\end{aligned}
$$

\subsection{Water Demand and Supply Forecasting}

Water demand forecasting is mainly used to forecast the water demand of Handan in 2035. It takes 2020 as the base year and uses the quota method [60] in combination with the long-term development planning of Handan. The water demand of the five types of water users in $2035(p=50 \%)$ is approximately $2740.43 \times 10^{6} \mathrm{~m}^{3}$. The results are presented in Table 1. The water demand forecast results are used as the upper limit of the water demand for each water user type in different subregions. The lower limit is $80 \%$ of the predicted volume.

Table 1. Prediction results of water demand in Handan City in $2035(p=50 \%)\left(10^{6} \mathrm{~m}^{3}\right)$.

\begin{tabular}{ccccccc}
\hline Subregion & Domestic & $\begin{array}{c}\text { Primary } \\
\text { Sector }\end{array}$ & $\begin{array}{c}\text { Secondary } \\
\text { Sector }\end{array}$ & $\begin{array}{c}\text { Tertiary } \\
\text { Sector }\end{array}$ & Ecology & Total \\
\hline Shexian & 20.70 & 19.20 & 12.66 & 15.38 & 17.83 & 85.77 \\
Wu'an & 36.58 & 95.38 & 46.20 & 38.50 & 21.63 & 238.29 \\
Fengfeng & 33.30 & 25.76 & 21.86 & 13.25 & 4.23 & 98.40 \\
Feixiang & 20.18 & 120.78 & 8.22 & 9.00 & 5.94 & 164.12 \\
Handan city & 105.27 & 122.59 & 41.82 & 80.38 & 16.09 & 366.15 \\
Yongnian & 41.71 & 137.50 & 21.40 & 17.09 & 9.06 & 226.76 \\
Guangping & 14.14 & 66.20 & 6.31 & 7.00 & 3.83 & 97.48 \\
Cheng'an & 18.97 & 91.73 & 14.65 & 10.63 & 5.81 & 141.79 \\
Guantao & 15.68 & 87.57 & 3.80 & 9.83 & 5.46 & 122.34 \\
Daming & 37.25 & 177.64 & 6.51 & 14.80 & 12.64 & 248.84 \\
Cixian & 22.74 & 51.07 & 4.81 & 8.87 & 8.35 & 95.84 \\
Weixian & 41.96 & 163.57 & 16.50 & 14.88 & 10.19 & 247.10 \\
Linzhang & 29.13 & 145.28 & 10.75 & 12.95 & 8.91 & 207.02 \\
Qiuxian & 10.80 & 88.77 & 6.00 & 7.51 & 5.36 & 118.44 \\
Quzhou & 10.60 & 129.00 & 10.15 & 2.00 & 8.11 & 159.86 \\
Jize & 15.13 & 87.99 & 7.35 & 7.72 & 4.04 & 122.23 \\
Total & 474.14 & 1610.03 & 238.99 & 269.79 & 147.48 & 2740.43 \\
\hline
\end{tabular}

According to the water resource conditions of Handan, the available water supply in 2035 is predicted. The prediction of the available water supply of local surface water, groundwater, and recycled water directly uses the results of the Third Water Resources Evaluation in Handan [61] and the Research Report on Development and Utilization of Reclaimed Water in Handan [62]. The water supplied by the South-North Transfer Project directly uses the results from the Supporting Works Plan in Handan for the South-North Water Transfer Project (Middle Line) in Hebei Province [63]. The reservoir water, the Yellow River, and the Weihe River use the available allocated results listed in the Allocation and Utilization of Surface Water in Handan [64]. The total water supplied in Handan in 2035 is approximately $2734.13 \times 10^{6} \mathrm{~m}^{3}$. Table 2 lists the water supply by different water resources in each subregion of Handan in 2035 ( $p=50 \%$ ). 
Table 2. Prediction results of available water supply in Handan in $2035(p=50 \%)\left(10^{6} \mathrm{~m}^{3}\right)$.

\begin{tabular}{|c|c|c|c|c|c|c|c|}
\hline Subregions & $\begin{array}{c}\text { Local surface } \\
\text { Water }\end{array}$ & $\begin{array}{l}\text { Ground } \\
\text { Water }\end{array}$ & $\begin{array}{l}\text { Reservoir } \\
\text { Water }\end{array}$ & $\begin{array}{c}\text { Yellow River } \\
\text { Transferred } \\
\text { Water }\end{array}$ & $\begin{array}{c}\text { Weihe } \\
\text { Transferred } \\
\text { Water }\end{array}$ & $\begin{array}{c}\text { South-North } \\
\text { Transferred } \\
\text { Water }\end{array}$ & $\begin{array}{c}\text { Recycled } \\
\text { Water }\end{array}$ \\
\hline Shexian & 107.75 & 62.33 & & & & & 16.13 \\
\hline Wu'an & 60.32 & 76.80 & & & & & 39.89 \\
\hline Fengfeng & 108.53 & 66.56 & & & & & 29.00 \\
\hline Feixiang & 2.70 & 19.39 & $\sqrt{ }$ & $\sqrt{ }$ & & 10.00 & 14.99 \\
\hline Handan City & 1.93 & 119.57 & $\sqrt{ }$ & & & 193.73 & 86.24 \\
\hline Yongnian & 21.76 & 80.24 & $\sqrt{ }$ & & & 36.00 & 30.47 \\
\hline Guangping & 0.47 & 15.03 & $\sqrt{ }$ & $\sqrt{ }$ & & 7.00 & 10.31 \\
\hline Cheng'an & 0.73 & 51.91 & $\sqrt{ }$ & & & 6.74 & 14.56 \\
\hline Guantao & 1.36 & 49.55 & $\sqrt{ }$ & $\sqrt{ }$ & $\sqrt{ }$ & 7.00 & 10.61 \\
\hline Daming & 1.28 & 107.71 & $\sqrt{ }$ & $\sqrt{ }$ & $\sqrt{ }$ & 7.90 & 23.81 \\
\hline Cixian & 28.77 & 66.79 & $\sqrt{ }$ & & & 30.74 & 15.62 \\
\hline Weixian & 2.03 & 73.12 & $\sqrt{ }$ & $\sqrt{ }$ & $\sqrt{ }$ & 21.00 & 28.82 \\
\hline Linzhang & 0.30 & 91.46 & $\sqrt{ }$ & & & 7.38 & 19.45 \\
\hline Qiuxian & 1.67 & 19.67 & $\sqrt{ }$ & $\sqrt{ }$ & & 13.00 & 7.90 \\
\hline Quzhou & 4.92 & 6.15 & $\sqrt{ }$ & $\sqrt{ }$ & & 5.53 & 18.39 \\
\hline Jize & 1.05 & 23.71 & $\sqrt{ }$ & $\sqrt{ }$ & & 6.00 & 11.12 \\
\hline Total & 345.57 & 929.99 & 560.51 & 138.73 & 30.00 & 352.02 & 377.31 \\
\hline
\end{tabular}

\subsection{Model Parameter Determination}

\subsubsection{Coefficient of Water Supply Efficiency $b_{i j}^{\mathrm{k}}$}

A large value is generally assigned to the water supply benefit coefficient to ensure the priority of water supply to domestic water. The efficiency coefficients for domestic water use were $800 \mathrm{CNY} / \mathrm{m}^{3}$. The water supply efficiency coefficients of the primary, secondary, and tertiary sectors are 15,500 , and 480 yuan $/ \mathrm{m}^{3}$, respectively. The usage of ecological water can better reflect sustainable development. In addition, the value of the ecological water use efficiency coefficient is generally high, which is $800 \mathrm{CNY} / \mathrm{m}^{3}$.

\subsubsection{Coefficient of Water Supply Cost $c_{i j}^{\mathrm{k}}$}

According to the latest water supply cost, the water supply coefficients for domestic, primary, secondary, tertiary, and ecological water use are $5.2 \mathrm{CNY} / \mathrm{m}^{3}, 0.2 \mathrm{CNY} / \mathrm{m}^{3}$, 9.0 CNY $/ \mathrm{m}^{3}, 7.0 \mathrm{CNY} / \mathrm{m}^{3}$, and $3.2 \mathrm{CNY} / \mathrm{m}^{3}$.

\subsubsection{Coefficient of Water Supply Sequence $\alpha_{i}^{\mathrm{k}}$}

The water supply sequence coefficient reflects the priority of the $i$-th water source relative to other water sources in subregion $k$. It can be calculated using Equation (22) [65].

$$
\alpha_{k i}=\frac{1+n_{k \max }-n_{k i}}{\sum_{i=1}^{I}\left(1+n_{k \max }-n_{k i}\right)},
$$

where $n_{k i}$ is the water supply order of source $i$ in subregion $k$ and $n_{k \max }$ is the maximum order.

We calculated the water supply sequence coefficients of seven water sources in the Handan water resources allocation optimization model, in which the water supply sequence coefficients were assumed to be the same in all subregions. Table 3 lists the water supply sequence coefficients corresponding to different water user types supplied by different water sources. 
Table 3. Coefficients of the water supply sequence to different water user types supplied by different water sources in Handan.

\begin{tabular}{cccccc}
\hline Water Supply & Domestic & $\begin{array}{c}\text { Primary } \\
\text { Sector }\end{array}$ & $\begin{array}{c}\text { Secondary } \\
\text { Sector }\end{array}$ & $\begin{array}{c}\text { Tertiary } \\
\text { Sector }\end{array}$ & Ecology \\
\hline Local surface water & & 0.29 & & & 0.30 \\
$\quad$ Ground water & 0.33 & 0.05 & 0.07 & 0.33 & 0.10 \\
$\quad$ Reservoir water & & 0.10 & 0.20 & & 0.67 \\
South to North-transferred water & 0.67 & & 0.33 & & 0.20 \\
Yellow River-transferred water & & 0.19 & 0.13 & & 0.40 \\
Weihe River-transferred water & & 0.14 & & & \\
$\quad$ Recycled water & & 0.24 & 0.27 & & \\
\hline
\end{tabular}

\subsubsection{Coefficient of Water Supply Fairness $\lambda_{j}^{\mathrm{k}}$}

The water supply fairness coefficient $\lambda_{j}^{k}$ measures the priority of user $j$ receiving water supply relative to other users in subregion $k . \lambda_{j}^{k}$ and $\alpha_{j}^{k}$ are similar coefficients, and can be obtained using Equation (22). The priority of water supply is set as domestic, ecological, second sector, tertiary sector, and primary sector. The corresponding water supply fairness coefficients of the water users are $0.33,0.27,0.20,0.13$, and 0.07 , respectively.

\section{Results and Discussions}

\subsection{Results Analysis}

In this study, AMOGWO was used to solve the multi-objective optimal allocation model of water resources in Handan. The population number was 1000, and the number of iterations was 500. MATLAB was used as a solution tool to obtain the Pareto front. Figure 4 shows the iterative process of the individual average value of the AMOGWO algorithm swarm. It is apparent that the iteration curve of the individual average value of the social benefit objective function and the economic benefit objective function tends to converge at approximately 180 iterations. After 180 iterations, it fluctuates within a small range but exhibits a stable trend. The AMOGWO algorithm has a fast convergence speed.

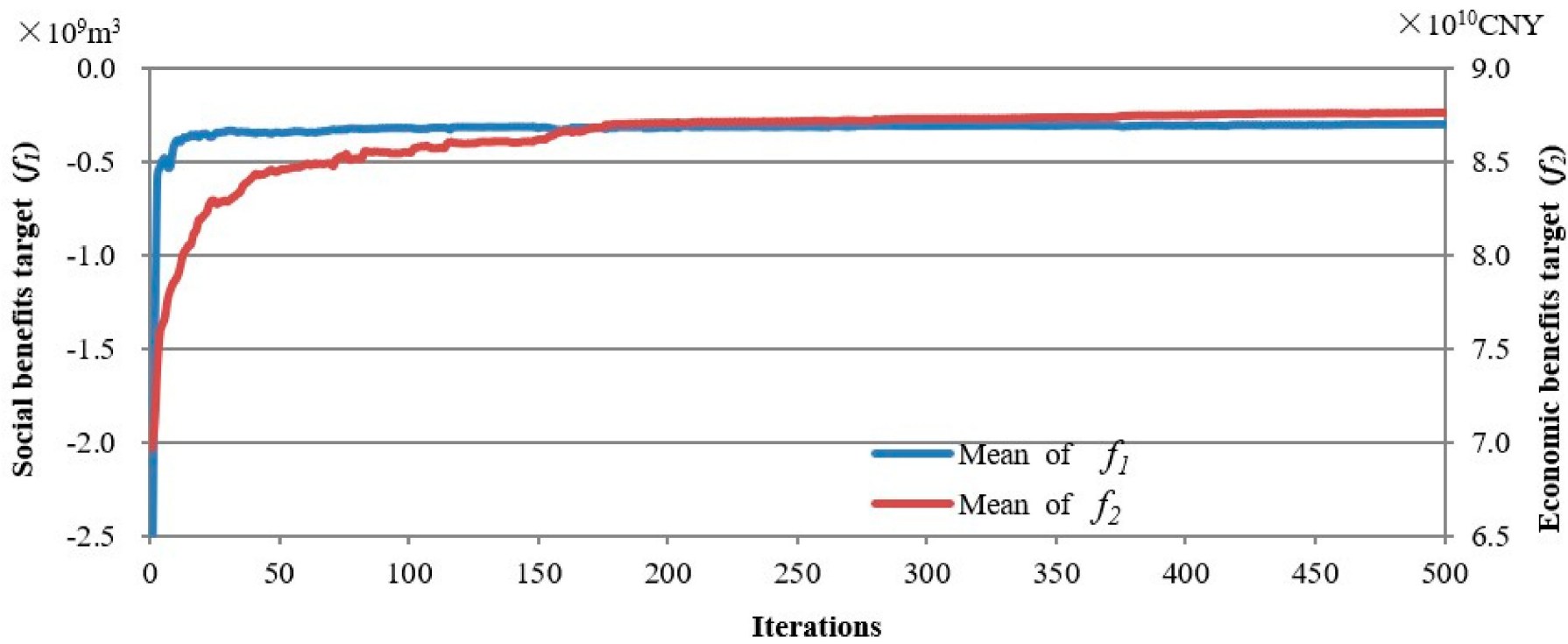

Figure 4. Iterative process of the individual average value of AMOGWO swarm.

Moreover, we obtained the Pareto optimal solution set from the model calculation results, which provided more choices for decision-makers. Note that this solution set cannot provide the optimal option for decision-makers. The decision-makers must obtain the final scenario based on their preference and compromise between objectives. Moreover, there is a serious water shortage in Handan. Meeting the water demand of different water 
users is an urgent problem that needs to be solved in current water resource management. The minimum water shortage scenario should reflect the requirements of regional water resource management. Therefore, this paper chooses it as an effective scenario and analyzes it in detail.

The Handan water resources optimal allocation model in 2035 ( $p=50 \%$ ) yields a total water demand of $2740.43 \times 10^{6} \mathrm{~m}^{3}$, a total water distribution of $2442.23 \times 10^{6} \mathrm{~m}^{3}$, a water shortage of $298.20 \times 10^{6} \mathrm{~m}^{3}$, and a water shortage rate of $10.9 \%$. From the perspective of water users, the water allocated to domestic water users and ecological water users can meet the water demand and achieve a balance between supply and demand (see Table 4). The primary, secondary, and tertiary sectors experience water shortages in some regions. The total water demand of the primary sector, total water distribution, and total water shortage are $1610.02 \times 10^{6} \mathrm{~m}^{3}, 1339.03 \times 10^{6} \mathrm{~m}^{3}$, and $271.00 \times 10^{6} \mathrm{~m}^{3}$, respectively, accounting for $16.8 \%$ of the water demand of the primary sector. All subregions lack water except for Shexian, Fengfeng, and Handan. Moreover, the water demand of the secondary sector is $238.99 \times 10^{6} \mathrm{~m}^{3}$, and the total water allocation is $214.21 \times 10^{6} \mathrm{~m}^{3}$. Note that only $\mathrm{Wu}^{\prime}$ an fails to reach the balance of supply and demand, with a total water shortage of $24.78 \times 10^{6} \mathrm{~m}^{3}$, accounting for $10.4 \%$ of the water demand of the secondary sector. The total water demand of the tertiary sector is $269.79 \times 10^{6} \mathrm{~m}^{3}$, and the total water distribution is $267.37 \times 10^{6} \mathrm{~m}^{3}$. Specifically, Feixiang and Quzhou do not achieve a balanced supply and demand, and the total water shortage is $2.42 \times 10^{6} \mathrm{~m}^{3}$, accounting for $0.9 \%$ of the water demand of the tertiary sector. According to the statistical analysis of water shortage, there is severe water shortage in the primary sector, which accounts for $90.9 \%$ of the total water shortage, and followed by the secondary sector with a water shortage rate of $8.3 \%$. Finally, the tertiary sector has a water shortage rate of $0.8 \%$.

From the perspective of water supply, the total water allocation is $2442.23 \times 10^{6} \mathrm{~m}^{3}$ in $2035(p=50 \%)$, which includes local surface water $(7.0 \%)$, groundwater $(35.2 \%)$, reservoir water $(23.0 \%)$, Yellow River-transferred water $(5.7 \%)$, Weihe-transferred water $(1.2 \%)$, South-North-transferred water (14.3\%), and recycled water (13.6\%; Table 5).

Figure 5a shows the allocation of different water sources to each subregion in Handan. The available water supply of local surface water is $345.57 \times 10^{6} \mathrm{~m}^{3}$, and the actual water supply is $172.04 \times 10^{6} \mathrm{~m}^{3}$. The supply object includes two water users-primary sector and ecological-where $147.72 \times 10^{6} \mathrm{~m}^{3}$ water is supplied to primary sector and $24.32 \times 10^{6} \mathrm{~m}^{3}$ for ecological environment. Meanwhile, the remaining available water supply is $173.53 \times 10^{6} \mathrm{~m}^{3}$, which is concentrated in Shexian $\left(77.65 \times 10^{6} \mathrm{~m}^{3}\right)$, Fengfeng $\left(82.84 \times 10^{6} \mathrm{~m}^{3}\right)$, and Cixian $\left(13.04 \times 10^{6} \mathrm{~m}^{3}\right)$. Figure $5 \mathrm{~b}$ illustrates the groundwater allocation in each subregion in Handan. The available water supply of groundwater resources is $929.99 \times 10^{6} \mathrm{~m}^{3}$, and its actual water supply is $858.99 \times 10^{6} \mathrm{~m}^{3}$, which are allocated to the domestic $\left(222.06 \times 10^{6} \mathrm{~m}^{3}\right)$, primary $\left(450.64 \times 10^{6} \mathrm{~m}^{3}\right)$, secondary $\left(8.13 \times 10^{6} \mathrm{~m}^{3}\right)$, and tertiary $\left(178.16 \times 10^{6} \mathrm{~m}^{3}\right)$.

Figure $5 c$ shows the distribution of reservoir water, which is supplied to the users of the primary sector, secondary sector, and ecological environment. Its water supply is $560.51 \times 10^{6} \mathrm{~m}^{3}$, the actual water supply is $560.51 \times 10^{6} \mathrm{~m}^{3}$, and there is no surplus water. In the water distribution, $495.21 \times 10^{6} \mathrm{~m}^{3}$ of water is supplied to the primary sector, $62.76 \times 10^{6} \mathrm{~m}^{3}$ to the secondary sector, and $2.54 \times 10^{6} \mathrm{~m}^{3}$ to the ecological environment.

The water distribution of the Yellow River mainly involves Quzhou, Weixian, Guangping, Feixiang, Daming, Guantao, Jize, and Qiuxian, which is shown in Figure 5d. The water supply of Yellow River is $138.73 \times 10^{6} \mathrm{~m}^{3}$, and its actual water supply is $138.73 \times 10^{6} \mathrm{~m}^{3}$. The supply targets include the users of the primary sector, secondary sector, and ecological environment. The supply of primary sector water is $119.65 \times 10^{6} \mathrm{~m}^{3}$, secondary sector is $11.29 \times 10^{6} \mathrm{~m}^{3}$, and ecological environment is $7.79 \times 10^{6} \mathrm{~m}^{3}$. The remaining available water supply is zero. 
Table 4. Water distribution results per user type in Handan in $2035(p=50 \%)\left(10^{6} \mathrm{~m}^{3}\right)$.

\begin{tabular}{|c|c|c|c|c|c|c|c|c|c|c|c|c|c|c|c|c|c|c|}
\hline \multirow{2}{*}{ Subregion } & \multicolumn{3}{|c|}{ Domestic } & \multicolumn{3}{|c|}{ Primary Sector } & \multicolumn{3}{|c|}{ Secondary Sector } & \multicolumn{3}{|c|}{ Tertiary Sector } & \multicolumn{3}{|c|}{ Ecology } & \multicolumn{3}{|c|}{ Total } \\
\hline & Demand & Allocate & Shortage & Demand & Allocate & Shortage & Demand & Allocate & Shortage & Demand & Allocate & Shortage & Demand & Allocate & Shortage & Demand & Allocate & Shortage \\
\hline Shexian & 20.70 & 20.70 & 0 & 19.20 & 19.20 & 0 & 12.66 & 12.66 & 0 & 15.38 & 15.38 & 0 & 17.83 & 17.83 & 0 & 85.77 & 85.77 & 0 \\
\hline Wu'an & 36.58 & 36.58 & 0 & 95.38 & 58.88 & -36.50 & 46.20 & 21.42 & -24.78 & 38.50 & 38.50 & 0 & 21.63 & 21.63 & 0 & 238.29 & 177.01 & -61.28 \\
\hline Fengfeng & 33.30 & 33.30 & 0 & 25.76 & 25.76 & 0.0 & 21.86 & 21.86 & 0 & 13.25 & 13.25 & 0 & 4.23 & 4.23 & 0 & 98.40 & 98.40 & \\
\hline $\begin{array}{l}\text { Handan } \\
\text { City }\end{array}$ & 105.27 & 105.27 & 0 & 122.59 & 122.59 & 0.0 & 41.82 & 41.82 & 0 & 80.38 & 80.38 & 0 & 16.09 & 16.09 & 0 & 366.15 & 366.15 & 0 \\
\hline Yongnian & 41.71 & 41.71 & 0 & 137.50 & 127.42 & -10.08 & 21.40 & 21.40 & 0 & 17.09 & 17.09 & 0 & 9.06 & 9.06 & 0 & 226.76 & 216.68 & -10.08 \\
\hline Guangping & 14.14 & 14.14 & 0 & 66.20 & 26.99 & -39.21 & 6.31 & 6.31 & 0 & 7.00 & 7.00 & 0 & 3.83 & 3.83 & 0 & 97.48 & 58.27 & -39.21 \\
\hline Cheng'an & 18.97 & 18.97 & 0 & 91.73 & 54.10 & -37.63 & 14.65 & 14.65 & 0 & 10.63 & 10.63 & 0 & 5.81 & 5.81 & 0 & 141.79 & 104.16 & -37.63 \\
\hline Guantao & 15.68 & 15.68 & 0 & 87.57 & 82.07 & -5.50 & 3.80 & 3.80 & 0 & 9.83 & 9.83 & 0 & 5.46 & 5.46 & 0 & 122.34 & 116.84 & -5.50 \\
\hline Cixian & 22.74 & 22.74 & 0 & 51.07 & 51.07 & 0 & 4.81 & 4.81 & 0 & 8.87 & 8.87 & 0 & 8.35 & 8.35 & 0 & 95.84 & 95.84 & 0 \\
\hline Weixian & 41.96 & 41.96 & 0 & 163.57 & 153.07 & -10.50 & 16.50 & 16.50 & 0 & 14.88 & 14.88 & 0 & 10.19 & 10.19 & 0 & 247.10 & 236.60 & -10.50 \\
\hline Linzhang & 29.13 & 29.13 & 0 & 145.28 & 92.33 & -52.95 & 10.75 & 10.75 & 0 & 12.95 & 12.95 & 0 & 8.91 & 8.91 & 0 & 207.02 & 154.07 & -52.95 \\
\hline Qiuxian & 10.80 & 10.80 & 0 & 88.77 & 83.78 & -4.99 & 6.00 & 6.00 & 0 & 7.51 & 7.51 & 0 & 5.36 & 5.36 & 0 & 118.44 & 113.45 & -4.99 \\
\hline Quzhou & 10.60 & 10.60 & 0 & 129.00 & 116.21 & -12.79 & 10.15 & 10.15 & 0 & 2.00 & 0.45 & -1.55 & 8.11 & 8.11 & 0 & 159.86 & 145.52 & -14.34 \\
\hline Jize & 15.13 & 15.13 & 0 & 87.99 & 61.66 & -26.33 & 7.35 & 7.35 & 0 & 7.72 & 7.72 & 0 & 4.04 & 4.04 & 0 & 122.23 & 95.90 & -26.33 \\
\hline Total & 474.14 & 474.14 & 0 & 1610.03 & 1339.03 & -271.00 & 238.99 & 214.21 & -24.78 & 269.79 & 267.37 & -2.42 & 147.48 & 147.48 & 0 & 2740.43 & 2442.23 & -298.20 \\
\hline
\end{tabular}


Table 5. Water distribution results per water source in Handan in $2035(p=50 \%)\left(10^{6} \mathrm{~m}^{3}\right)$.

\begin{tabular}{|c|c|c|c|c|c|c|c|c|}
\hline Subregion & $\begin{array}{l}\text { Local } \\
\text { Surface } \\
\text { Water }\end{array}$ & $\begin{array}{l}\text { Ground } \\
\text { Water }\end{array}$ & $\begin{array}{l}\text { Reservoir } \\
\text { Water }\end{array}$ & $\begin{array}{l}\text { Yellow } \\
\text { River- } \\
\text { Transferred } \\
\text { Water }\end{array}$ & $\begin{array}{l}\text { Weihe- } \\
\text { Transferred } \\
\text { Water }\end{array}$ & $\begin{array}{l}\text { South- } \\
\text { North- } \\
\text { Transferred } \\
\text { Water }\end{array}$ & $\begin{array}{l}\text { Recycled } \\
\text { Water }\end{array}$ & Total \\
\hline Shexian & 30.10 & 39.54 & & & & & 16.13 & 85.77 \\
\hline Wu'an & 60.32 & 76.8 & & & & & 39.89 & 177.01 \\
\hline Fengfeng & 25.69 & 48.9 & & & & & 23.81 & 98.4 \\
\hline Feixiang & 2.70 & 19.39 & 57.85 & 29.72 & & 10.00 & 14.99 & 134.65 \\
\hline Handan City & 1.93 & 119.57 & 1.39 & & & 193.63 & 49.63 & 366.15 \\
\hline Yongnian & 21.76 & 80.24 & 48.21 & & & 36 & 30.47 & 216.68 \\
\hline Guangping & 0.47 & 15.03 & 21.52 & 3.99 & & 6.95 & 10.31 & 58.27 \\
\hline Cheng'an & 0.73 & 51.91 & 30.22 & & & 6.74 & 14.56 & 104.16 \\
\hline Guantao & 1.36 & 49.55 & 9.74 & 22.52 & 16.06 & 7.00 & 10.61 & 116.84 \\
\hline Daming & 1.28 & 107.71 & 85.40 & 10.10 & 6.72 & 7.90 & 23.81 & 242.92 \\
\hline Cixian & 15.73 & 36.24 & 1.34 & & & 30.66 & 11.87 & 95.84 \\
\hline Weixian & 2.03 & 73.12 & 83.89 & 20.52 & 7.22 & 21.00 & 28.82 & 236.6 \\
\hline Linzhang & 0.30 & 91.46 & 35.48 & & & 7.38 & 19.45 & 154.07 \\
\hline Qiuxian & 1.67 & 19.67 & 45.65 & 27.14 & & 11.42 & 7.90 & 113.45 \\
\hline Quzhou & 4.92 & 6.15 & 91.51 & 19.02 & & 5.53 & 18.39 & 145.52 \\
\hline Jize & 1.05 & 23.71 & 48.31 & 5.72 & & 5.99 & 11.12 & 95.9 \\
\hline Total & 172.04 & 858.99 & 560.51 & 138.73 & 30.00 & 350.2 & 331.76 & 2442.23 \\
\hline
\end{tabular}

As shown in Figure 5e, the Weihe transferred water is mostly distributed to Weixian, Daming, and Guantao for use by the primary sector. The water is completely allocated and there is no surplus; the total allocated volume is $30.0 \times 10^{6} \mathrm{~m}^{3}$.

Figure $5 \mathrm{f}$ shows the allocation results of water transferred through the South-North Water Transfer Project to each user in each subregion in Handan. The transferred water is mostly supplied for the domestic, secondary, and tertiary sectors. The total available water supply and total allocated volumes are $352.02 \times 10^{6} \mathrm{~m}^{3}$ and $350.20 \times 10^{6} \mathrm{~m}^{3}$, respectively, resulting in a surplus of $1.82 \times 10^{6} \mathrm{~m}^{3}$ that is not allocated for any use. The allocated volumes for domestic, secondary, and tertiary sector users are $252.08 \times 10^{6} \mathrm{~m}^{3}$, $8.91 \times 10^{6} \mathrm{~m}^{3}$, and $89.21 \times 10^{6} \mathrm{~m}^{3}$, respectively.

The allocation results for recycled water in Handan are shown in Figure 5g. The total available water supply is $377.31 \times 10^{6} \mathrm{~m}^{3}$ and the total allocated volume is $331.76 \times 10^{6} \mathrm{~m}^{3}$, resulting in a surplus of $45.55 \times 10^{6} \mathrm{~m}^{3}$. The reclaimed water is supplied to every subregion in Handan and is mostly allocated to the primary sector, secondary sector, and ecology in volumes of $95.81 \times 10^{6} \mathrm{~m}^{3}, 123.12 \times 10^{6} \mathrm{~m}^{3}$, and $112.83 \times 10^{6} \mathrm{~m}^{3}$, respectively. These account for $28.9 \%, 37.1 \%$, and $34.0 \%$ of the total allocated volume, respectively.

In summary, the total water demand of all users in Handan, total available water supply, total water distribution, and water shortage are $2740.43 \times 10^{6} \mathrm{~m}^{3}, 2734.14 \times 10^{6} \mathrm{~m}^{3}$, $2442.23 \times 10^{6} \mathrm{~m}^{3}$, and $298.20 \times 10^{6} \mathrm{~m}^{3}$, respectively. In addition, a surplus of $291.91 \times 10^{6} \mathrm{~m}^{3}$ is not allocated. The reservoir water, externally transferred water (i.e., water transferred via the South-North Water Transfer Project), water imported from the Yellow River, and water from the Weihe River are fully allocated. The remaining water includes local surface water, groundwater, South-North Water transfer water, and recycled water, which are $173.53 \times 10^{6} \mathrm{~m}^{3}, 71.0 \times 10^{6} \mathrm{~m}^{3}, 1.82 \times 10^{6} \mathrm{~m}^{3}$, and $45.5 \times 10^{6} \mathrm{~m}^{3}$, respectively. The surplus water is concentrated in Handan City, Shexian, Fengfeng, and Cixian. The remaining water cannot be used in other regions because of the lack of a water transfer project. Among the 16 subregions of Handan, only four regions can fully meet the balance between water supply and demand: Handan City, Shexian, Fengfeng, and Cixian. However, the other 12 regions lack water in varying degrees. The highest water shortage rate is in Guangping $(40.2 \%)$, followed by Cheng'an (26.5\%), Wuan (25.7\%), Linzhang (25.6\%), Jize $(21.5 \%)$, Feixiang (18.0\%), Quzhou (9.0\%), Guantao (4.5\%), Weixian (4.2\%), Qiuxian (4.2\%), Yongnian $(4.4 \%)$, and Daming $(2.4 \%)$. Water shortages in these regions can only be alleviated by conserving water. 

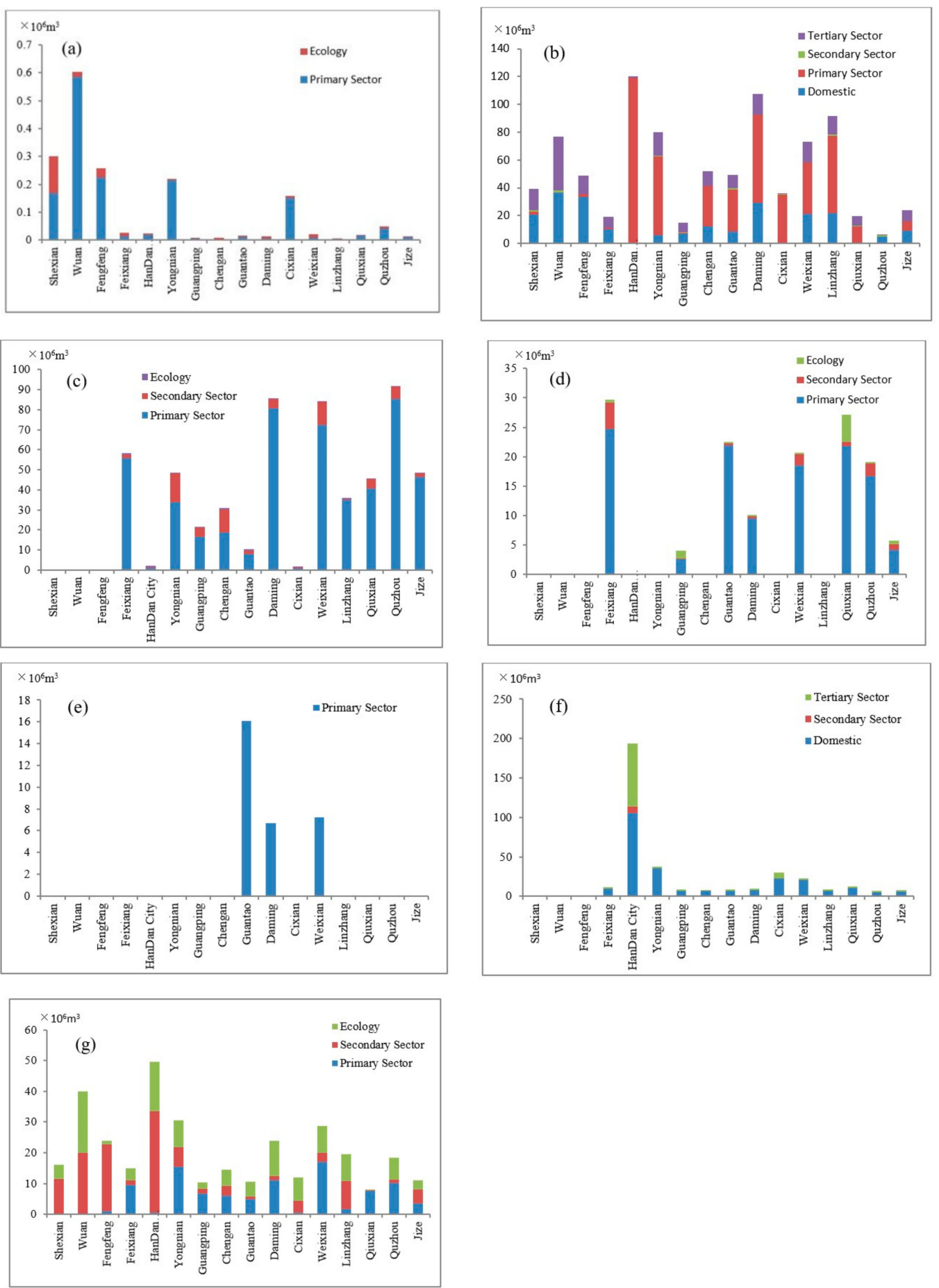

Figure 5. Distribution results of different water users supplied by each water source. (a) Local surface water, (b) groundwater, (c) reservoir water, (d) Yellow River-transferred water, (e) Weihe-transferred water, (f) South-North-transferred water, and (g) recycled water.

\subsection{Comparison with NSGA-II and MOPSO}

The literature shows that the most popular multi-objective meta-heuristic algorithm is NSGA-II [18], and the second is MOPSO [66]. Consequently, the AMOGWO algorithm was compared to NSGA-II and MOPSO to evaluate its effectiveness in solving the optimal allocation model of water resources. All parameters in NSGA-II and MOPSO were set the same to ensure a fair comparison. The initialization swarm size was 1000 and the number of iterations was 500. The other parameters in MOPSO were $c_{1}=0.002, c_{2}=0.002, \omega^{\prime}=0.9$, and $\omega^{\prime \prime}=0.2$, through numerous simulation experiments. 
For all three algorithms, the scenarios were chosen with preference for the minimum water shortage as the efficient solution, and to proceed with the comparative analysis. The calculation results obtained by the three algorithms are presented in Table 6 . The table shows that the greatest social benefit, that is, a minimum water shortage of $-298.20 \times 10^{6} \mathrm{~m}^{3}$, was obtained by AMOGWO. NSGA-II ranked second, with a social benefit of $-307.35 \times 10^{6} \mathrm{~m}^{3}$. MOPSO has the smallest social benefit at $-350.55 \times 10^{6} \mathrm{~m}^{3}$. Meanwhile, the economic benefit of AMOGWO is highest, followed by NSGA-II, and the lowest is by MOPSO. The detailed allocation results are listed in Tables 7 and 8 .

Table 6. Results for objective function values of AMOGWO, NSGA-II, and MOPSO.

\begin{tabular}{|c|c|c|}
\hline Algorithm & Social Benefit $\left(10^{6} \mathrm{~m}^{3}\right)$ & Economic Benefit $\left(10^{6} \mathrm{CNY}\right)$ \\
\hline AMOGWO & -298.20 & 87551.03 \\
\hline NSGA-II & -307.35 & 87272.81 \\
\hline MOPSO & -350.55 & 80116.27 \\
\hline
\end{tabular}

Table 7. Water distribution results of Handan obtained by NSGA-II $\left(10^{6} \mathrm{~m}^{3}\right)$.

\begin{tabular}{|c|c|c|c|c|c|c|c|c|}
\hline Subregions & $\begin{array}{l}\text { Local } \\
\text { Surface } \\
\text { Water }\end{array}$ & $\begin{array}{l}\text { Ground } \\
\text { Water }\end{array}$ & $\begin{array}{l}\text { Reservoir } \\
\text { Water }\end{array}$ & $\begin{array}{l}\text { Yellow } \\
\text { River } \\
\text { Trans- } \\
\text { ferred } \\
\text { Water }\end{array}$ & $\begin{array}{l}\text { Weihe } \\
\text { Trans- } \\
\text { ferred } \\
\text { Water }\end{array}$ & $\begin{array}{l}\text { South To } \\
\text { North } \\
\text { Trans- } \\
\text { ferred } \\
\text { Water }\end{array}$ & $\begin{array}{l}\text { Recycled } \\
\text { Water }\end{array}$ & Tatol \\
\hline Shexian & 29.54 & 38.12 & & & & & 16.11 & 83.77 \\
\hline Wu'an & 56.26 & 76.80 & & & & & 39.89 & 172.95 \\
\hline Fengfeng & 18.29 & 52.93 & & & & & 27.18 & 98.40 \\
\hline Feixiang & 2.70 & 19.39 & 81.27 & 20.98 & & 10.00 & 14.99 & 149.33 \\
\hline Handan City & 1.93 & 119.40 & 1.62 & & & 193.39 & 49.81 & 366.15 \\
\hline Yongnian & 21.76 & 80.24 & 15.44 & & & 36.00 & 30.47 & 183.91 \\
\hline Guangping & 0.47 & 15.03 & 60.01 & 2.31 & & 6.99 & 10.31 & 95.11 \\
\hline Cheng'an & 0.73 & 51.91 & 54.43 & & & 6.62 & 14.56 & 128.25 \\
\hline Guantao & 1.36 & 49.55 & 37.39 & 5.90 & 3.61 & 7.00 & 10.61 & 115.42 \\
\hline Daming & 1.28 & 107.71 & 77.07 & 5.14 & 2.49 & 7.90 & 23.81 & 225.39 \\
\hline Cixian & 27.87 & 20.66 & 3.05 & & & 30.74 & 12.59 & 94.91 \\
\hline Weixian & 2.03 & 73.12 & 54.86 & 21.27 & 23.20 & 21.00 & 28.82 & 224.31 \\
\hline Linzhang & 0.30 & 91.46 & 55.61 & & & 7.38 & 19.45 & 174.20 \\
\hline Qiuxian & 1.67 & 19.67 & 36.41 & 27.77 & & 13.00 & 7.90 & 106.42 \\
\hline Quzhou & 4.92 & 6.15 & 28.16 & 39.98 & & 5.53 & 18.39 & 103.13 \\
\hline Jize & 1.05 & 23.71 & 54.28 & 15.38 & & 5.89 & 11.12 & 111.43 \\
\hline Total & 172.16 & 845.85 & 559.60 & 138.73 & 29.30 & 351.44 & 336.01 & 2433.08 \\
\hline
\end{tabular}

By comparing the iterative process of the three algorithms, it is apparent from Figures 4, 6 and 7 that although the iteration curve of AMOGWO fluctuates, the fluctuation amplitude is relatively small, and the curve converges relatively quickly. In contrast, the swarm in MOPSO does not converge at the 180th iteration, and NSGA-II becomes stable at the 340th iteration. In summary, AMOGWO has a better convergence rate and precision than NSGA-II and MOPSO.

\subsection{Discussion}

As a new swarm-based meta-heuristic algorithm, the GWO algorithm has the advantages of simple principle, few parameters to adjust, easy implementation, and strong global search ability. It has been applied for the optimal allocation of water resources [67]. However, the traditional GWO has various disadvantages, including premature convergence, slow convergence speed in the later stage, and easily falling into local optimization [68]. Aiming at the shortcomings of GWO, many scholars have made improvements that improve its performance. The improvements are primarily focused on initialization population, 
search mechanism, and parameters. In traditional GWO, the initial population is generated based on random initialization, which cannot ensure good population diversity. Luo et al. proposed an improved GWO algorithm based on complex numerical coding [69]. Madhiarasan et al. reduced the grouping the of gray wolf population and classified the subordinate wolf group and the lowest level wolf group into one population, thereby reducing the computational complexity and increasing the convergence speed of the algorithm [70]. Long et al. used the good point set theory to initialize the population [71]. To improve the search mechanism, Saremi et al. introduced an evolutionary population dynamics (EPD) operator into GWO to enhance its exploration ability [72]. Gholizadeh et al. proposed an efficient GWO algorithm based on sequential implementation [73]. In the improvement for parameters, Long et al. balanced the exploration ability and development ability of the GWO algorithm by adjusting the adaptive value of parameter $a$ [74]. Mittal et al. used the exponential function to attenuate $a$ in the iterative process of the algorithm [75].

Since applying GWO algorithm directly to multi-objective optimization problems has some disadvantages, the MOGWO is proposed. It solves the problem of using GWO for multi-objective, but it does not improve the drawback of small search range and fast convergence in the early stage, and large search range and low accuracy in the later stage. To solve this problem, AMOGWO is proposed in this study. AMOGWO incorporates an improved calculation method for the distance control parameter $a$, adds a crowding degree for the archive, and optimizes the selection mechanism for leader wolves. It can be concluded from Figure 4 and Table 6 that after AMOGWO is applied to the multi-objective optimization of water resources allocation model in Handan, it speeds up the algorithm convergence and improves its accuracy.

In this study, we compared AMOGWO with NSGA-II and MOPSO, which represent the most popular multi-objective meta-heuristic algorithms, to verify its superiority in the multi-objective water resources allocation model. According to previous research results, the efficiency of the water resources allocation problem can be effectively improved under NSGA-II and MOPSO [76-81]. AMOGWO outperforms NSGA-II and MOPSO in terms of convergence rate and solution accuracy, as evidenced in Figures 4, 6 and 7, and Table 6. AMOGWO thus provides a new way to solve the complex multi-objective optimization of the water resources allocation model.

Table 8. Water distribution results of Handan obtained by MOPSO $\left(10^{6} \mathrm{~m}^{3}\right)$.

\begin{tabular}{|c|c|c|c|c|c|c|c|c|}
\hline Subregions & $\begin{array}{l}\text { Local } \\
\text { Surface } \\
\text { Water }\end{array}$ & $\begin{array}{l}\text { Ground } \\
\text { Water }\end{array}$ & $\begin{array}{l}\text { Reservoir } \\
\text { Water }\end{array}$ & $\begin{array}{l}\text { Yellow River } \\
\text { Transferred } \\
\text { Water }\end{array}$ & $\begin{array}{l}\text { Weihe } \\
\text { Transferred } \\
\text { Water }\end{array}$ & $\begin{array}{l}\text { South To } \\
\text { North } \\
\text { Transferred } \\
\text { Water }\end{array}$ & $\begin{array}{l}\text { Recycled } \\
\text { Water }\end{array}$ & Tatol \\
\hline Shexian & 30.31 & 47.90 & & & & & 7.56 & 85.77 \\
\hline Wu'an & 60.32 & 76.81 & & & & & 39.89 & 177.02 \\
\hline Fengfeng & 24.87 & 62.06 & & & & & 11.47 & 98.4 \\
\hline Feixiang & 2.70 & 19.39 & 61.14 & 18.30 & & 10.00 & 14.99 & 126.52 \\
\hline Handan City & 1.93 & 119.57 & 18.69 & & & 157.25 & 68.71 & 366.15 \\
\hline Yongnian & 21.76 & 80.24 & 40.91 & & & 32.51 & 30.47 & 205.89 \\
\hline Guangping & 0.47 & 15.03 & 42.56 & 16.79 & & 7.00 & 10.31 & 92.16 \\
\hline Cheng'an & 0.73 & 51.91 & 52.10 & & & 6.74 & 14.56 & 126.04 \\
\hline Guantao & 1.36 & 49.31 & 34.91 & 14.87 & 9.07 & 7.00 & 5.82 & 122.34 \\
\hline Daming & 1.28 & 107.71 & 39.57 & 17.74 & 12.34 & 7.90 & 23.81 & 210.35 \\
\hline Cixian & 17.51 & 31.99 & 18.67 & & & 19.75 & 7.92 & 95.84 \\
\hline Weixian & 2.03 & 73.12 & 47.70 & 18.54 & 8.59 & 21.00 & 28.82 & 199.80 \\
\hline Linzhang & 0.30 & 91.46 & 42.97 & & & 7.38 & 19.45 & 161.56 \\
\hline Qiuxian & 1.67 & 19.67 & 56.15 & 19.66 & & 9.81 & 7.90 & 114.86 \\
\hline Quzhou & 4.92 & 6.15 & 44.26 & 16.05 & & 5.53 & 18.39 & 95.30 \\
\hline Jize & 1.05 & 23.71 & 53.20 & 16.79 & & 6.00 & 11.12 & 111.87 \\
\hline Total & 173.21 & 876.03 & 552.83 & 138.74 & 30.00 & 297.87 & 321.19 & 2389.87 \\
\hline
\end{tabular}




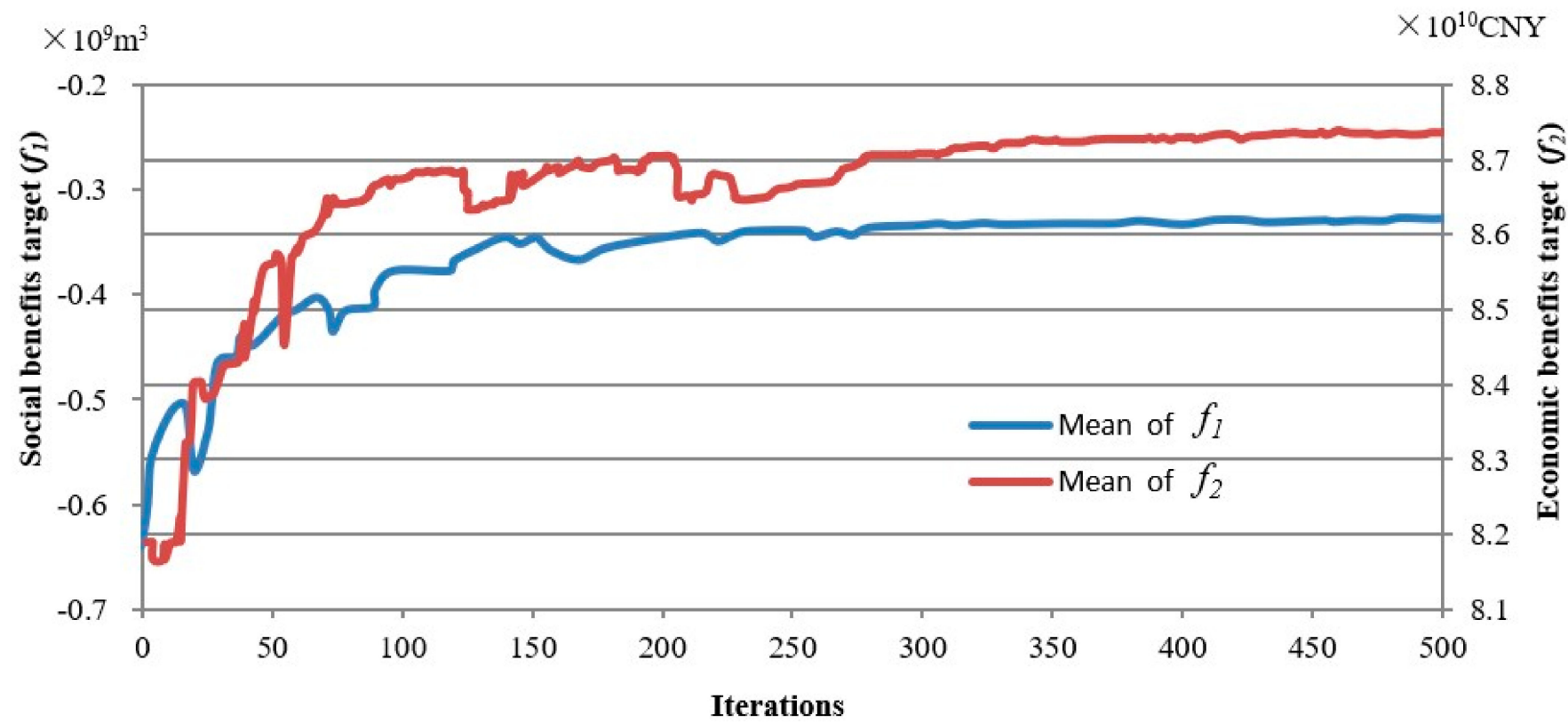

Figure 6. Iterative process of NSGA-II.

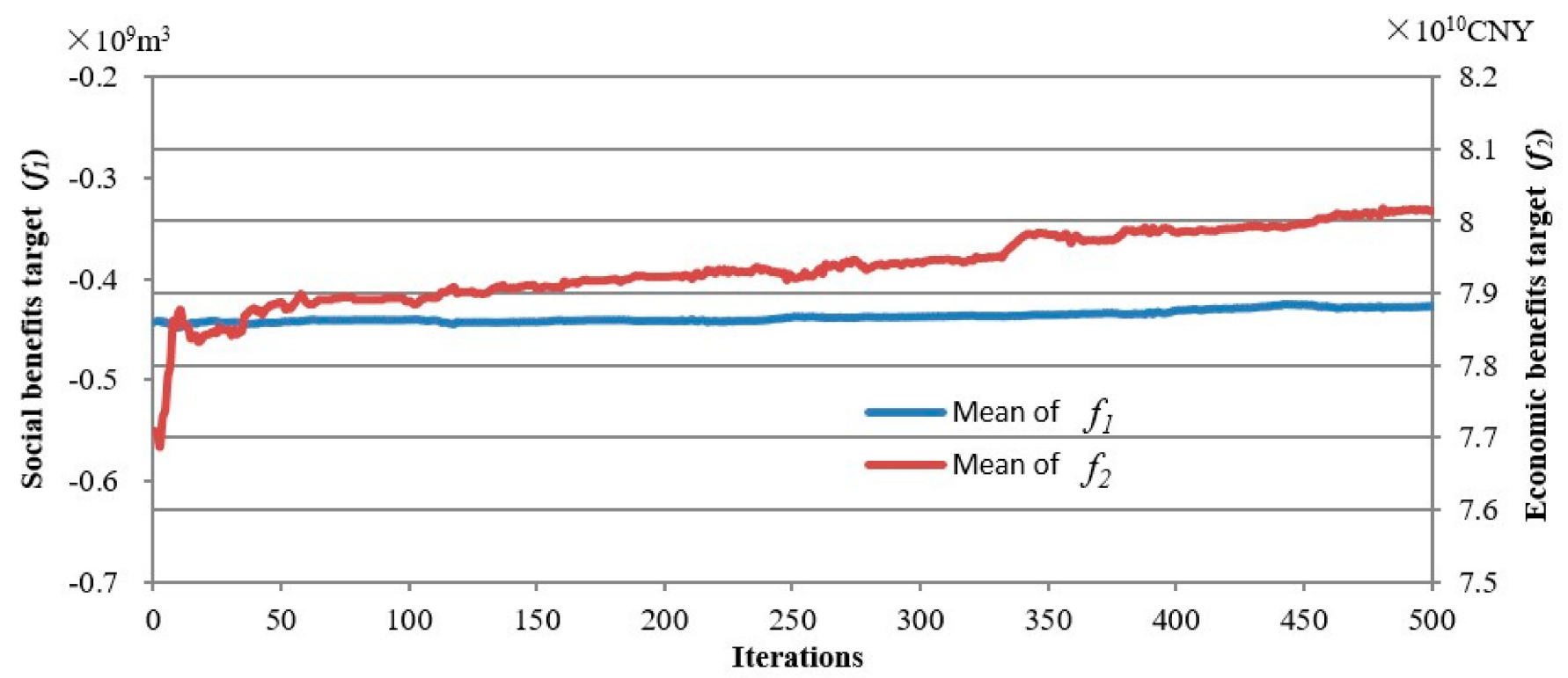

Figure 7. Iterative process of MOPSO.

\section{Conclusions}

In this study, an ameliorative multi-objective grey wolf optimizer (AMOGWO) was proposed, and was used on a multi-objective water resource allocation model with the maximum economic benefit and minimum water shortage as the objective function, which example is in Handan, China. The Pareto optimal frontier of the multi-objective optimization problem was obtained. In single-objective optimization, solutions can be compared easily due to the unary objective function. However, the solutions in a multi-objective space cannot be compared by the relational operators due to multi-criterion comparison metrics. Therefore, the decision-maker must obtain the final scenario based on his preference and compromise between objectives. The detailed allocation of the local surface water, groundwater, South to North transfer water, Yellow River transferred water, Weihe transferred water, and recycled water from Handan in $2035(p=50 \%)$ were obtained using the minimum water shortage as the criterion and selecting the best scheme from the Pareto optimal frontier. The total water demand, total water distribution, and water shortage are 
$2740.43 \times 10^{6} \mathrm{~m}^{3}, 2442.23 \times 10^{6} \mathrm{~m}^{3}$, and $298.20 \times 10^{6} \mathrm{~m}^{3}$, respectively. The total water shortage rate is $10.9 \%$, which is concentrated in the primary sector and accounts for $90.9 \%$ of the total water shortage. The allocation results agree with the principles of water resource utilization in Handan and can provide technical support and help in decision-making for water resource allocation.

Furthermore, the AMOGWO algorithm can adapt better to the multi-objective optimal allocation of water resources and has certain advantages in convergence and iteration compared with NSGA-II and MOPSO. This proves that the AMOGWO algorithm is effective in solving the problem of optimal allocation of water resources.

In this study, the AMOGWO algorithm only solves the optimal allocation of water resources with two objective functions. It is impossible to find a general algorithm that can solve all types of multi-objective optimization problems. Whether the AMOGWO algorithm is suitable for more than two objective functions needs to be ascertained in future work.

Author Contributions: This paper is a joint effort by several authors. Conceptualization, S.L. and Z.Y.; methodology, S.L. and J.S.; validation, D.X. and B.L.; data collection and processing, J.G., B.H., Y.C., Y.H., Z.X. and B.S.; writing-original draft preparation, S.L.; writing-review and editing, J.S. and Z.Y. All authors have read and agreed to the published version of the manuscript.

Funding: This research was funded by the Postgraduate Innovation Ability Funding Project of Hebei Province, grant number CXZZBS2018122.

Institutional Review Board Statement: Not applicable.

Informed Consent Statement: Not applicable.

Data Availability Statement: All data used during the study are proprietary or confidential and may only be provided with restrictions.

Acknowledgments: The authors are thankful for support from Hebei University of Engineering.

Conflicts of Interest: The authors declare no conflict of interest. The funders had no role in the design of the study; in the collection, analyses, or interpretation of data; in the writing of the manuscript, or in the decision to publish the results.

\section{References}

1. Vörösmary, C.J.; McIntyre, P.B.; Gessner, M.O.; Dudgeon, D.; Prusevich, A.; Green, P.; Glidden, S.; Bunn, S.E.; Sullivan, C.A.; Liermann, C.R.; et al. Global threats to human water security and river biodiversity. Nature 2010, 467, 555-561. [CrossRef]

2. Frederick, K.D.; Major, D.C. Climate change and water resources. Clim. Chang. 1997, 37, 7-23. [CrossRef]

3. Forsee, W.J.; Ahmad, S. Evaluating urban stormwater infrastructure design in response to projected climate change. J. Hydrol. Eng. 2011, 16, 865-873. [CrossRef]

4. Dawadi, S.; Ahmad, S. Evaluating the impact of demand-side management on water resources under changing climatic conditions and increasing population. J. Environ. Manag. 2013, 114, 261-275. [CrossRef] [PubMed]

5. Wang, X.; Wang, K.; Yang, W.T.; Xi, X.J.; Shi, L.Y.; Dong, W.Y.; Zhang, Q.; Zhou, Y.N. Shortage of Water Resources in China and Countermeasures. Environ. Eng. 2014, 7, 1-5.

6. Jiang, J.Q. Current situation analysis of water resources in China and Countermeasures for sustainable development. Intell. City 2019, 5, 44-45.

7. Xu, X.Y.; Wang, H.; Gan, H. Theory and Method of Macroeconomic Water Resources Planning in North China; Yellow River Water Conservancy Press: Zhengzhou, China, 1997. (In Chinese)

8. Branke, J.; KauSler, T.; Schmeck, H. Guidance in evolutionary multi-objective optimization. Adv. Eng. Softw. 2001, 32, 499-507. [CrossRef]

9. Marler, R.T.; Arora, J.S. Survey of multi-objective optimization methods for engineering. Struct. Multidiscip. Optim. 2004, 26, 369-395. [CrossRef]

10. Fang, H.S. Research of Elitist NSGA and Its Application in Regional Water Resources Optimal Allocation. Master's Thesis, Zhongbei University, Taiyuan, China, 2008. (In Chinese)

11. Deb, K.; Gupta, H. Introducing Robustness in Multi-Objective Optimization; MIT Press: Cambridge, UK, 2006.

12. Wang, L.P.; Ren, Y.; Qiu, Q.C.; Qiu, F.Y. Survey on Performance Indicators for Multi-Objective Evolutionary Algorithms. Chin. J. Comput. 2021, 44, 1590-1619. 
13. Coello Coello, C.A. Evolutionary multi-objective optimization: A historical view of the field. Comput. Intell. Mag. IEEE 2006, 1, 28-36. [CrossRef]

14. Coello Coello, C.A. An Updated Survey of Evolutionary Multi objective Optimization Techniques: State of the Art and Future Trends. Diabète Métabolisme 1999, 6, 109-119.

15. Whitley, D. A genetic algorithm tutorial. Stat. Comput. 1994, 4, 65-85. [CrossRef]

16. Storn, R.; Price, K. Differential evolution-A simple and efficient heuristic for global optimization over continuous spaces. J. Glob. Optim. 1997, 11, 341-359. [CrossRef]

17. Zitzler, E.; Thiele, L. Multiobjective evolutionary algorithms: A comparative case study and the strength pareto approach. IEEE Trans. Evol. Comput. 1999, 3, 257-271. [CrossRef]

18. Srinivas, N.; Deb, K. Muiltiobjective optimization using nondominated sorting in genetic algorithms. Evol. Comput. 1994, 2, 221-248. [CrossRef]

19. Deb, K.; Pratap, A.; Agarwal, S.; Meyarivan, T. A fast and elitist multiobjective genetic algorithm: NSGA-II. Evol. Comput. IEEE Trans. 2002, 6, 182-197. [CrossRef]

20. Rosenberg, R.S. Simulation of Genetic Populations with Biochemical Properties; University of Michigan: Ann Arbor, MI, USA, 1967.

21. Holland, J.H. Adaption in Natural and Artificial Systems; The University of Michigan Press: Ann Arbor, MI, USA, 1975.

22. Schaffer, J.D. Multiple Objective Optimization with Vector Evaluated Genetic Algorithms. Genetic Algorithms and Their Applications. In Proceedings of the First International Conference on Genetic Algorithms, Hillsdale, NJ, USA, 24-26 July 1985; pp. 93-100.

23. Fonseca, C.M.; Fleming, P.J. Genetic Algorithms for Multi-objective Optimization: Formulation Discussion and Generalization C. In Proceedings of the Fifth International Conference on Genetic Algorithms, San Francisco, CA, USA, 1 January 1993; pp. 416-423.

24. Zitzler, E.; Laumanns, M.; Thiele, L. SPEA2: Improving the Strength Pareto Evolutionary Algorithm C. Evolutionary Methods for Design, Optimization and Control with Applications to Industrial Problems; Springer-Verlag: Berlin, Germany, 2002; pp. 95-100.

25. Coello Coello, C.A.; Pulido, G.T. A Micro-Genetic Algorithm for Multiobjective Optimization. In Evolutionary Multi-Criterion Optimization, Proceedings of the EMO 2001, Zurich, Switzerland, 7-9 March 2001; Zitzler, E., Thiele, L., Deb, K., Coello Coello, C.A., Corne, D., Eds.; Lecture Notes in Computer Science; Springer: Heidelberg, Germany, 2001; Volume 1993. [CrossRef]

26. Rashedi, E.; Nezamabadi-Pour, H.; Saryazdi, S. GSA: A gravitational search algorithm. Inf. Sci. 2009, 179, 2232-2248. [CrossRef]

27. Webster, B.; Bernhard, P.J. A local search optimization algorithm based on natural principles of gravitation. In Proceedings of the 2003 International Conference on Information and Knowledge Engineering (IKE'03), Las Vegas, NV, USA, 23-26 June 2003; pp. 255-261.

28. Hatamlou, A. Black hole: A new heuristic optimization approach for data clustering. Inf. Sci. 2013, 222, 175-184. [CrossRef]

29. Kaveh, A.; Khayatazad, M. A new meta-heuristic method: Ray optimization. Comput. Struct. 2012, 112, 283-294. [CrossRef]

30. Shah-Hosseini, H. Principal components analysis by the galaxy-based search algorithm: A novel metaheuristic for continuous optimisation. Int. J. Comput. Sci. Eng. 2011, 6, 132-140.

31. Moghaddam, F.F.; Moghaddam, R.F.; Cheriet, M. Curved space optimization: A random search based on general relativity theory. arXiv 2012, arXiv:1208.2214.

32. Kennedy, J.; Eberhart, R. Particle swarm optimization. In Proceedings of the 1995 IEEE International Conference on Neural Networks, Perth, WA, Australia, 27 November-1 December 1995; 4, pp. 1942-1948.

33. Dorigo, M.; Birattari, M.; Stutzle, T. Ant colony optimization. IEEE Comput. Intell. 2006, 1, 28-39. [CrossRef]

34. Li, X.L.; Shao, Z.J.; Qian, J.X. An optimizing method based on autonomous animats: Fish-swarm algorithm. Syst. Eng. Theory Pract. 2002, 22, 32-38. (In Chinese)

35. Pan, W.T. A new fruit fly optimization algorithm: Taking the financial distress model as an example. Knowl. Based Syst. 2012, 26, 69-74. [CrossRef]

36. Mirjalili, S.; Lewis, A. The whale optimization algorithm. Adv. Eng. Softw. 2016, 95, 51-67. [CrossRef]

37. Zhu, H.P.; Li, W.J. Multiobjective Structural Optimization with Pareto Genetic Algorithm. J. Northwestern Polytech. Univ. 2001, 19, 152-155.

38. Kipouros, T.; Jaeggi, D.M.; Dawes, W.N.; Parks, G.T.; Savill, A.M.; Clarkson, P.J. Biobjective design optimization for axial compressors using Tabu Search. AIAA J. 2008, 46, 701-711. [CrossRef]

39. Luh, G.C.; Chueh, C.H. Multi-objective optimal design of truss structure with immune algorithm. Comput. Struct. 2004, 82, 829-844. [CrossRef]

40. Guo, H.F.; Ma, H.B.; Dong, Z.C.; Qin, X.B. The Aplication of Improved Multi-objective Particle Swarm Optimization Algorithm to Water Resources Allocation of Poyang Lake. China Rural Water Hydropower 2012, 10, 61-64. (In Chinese)

41. Wu, A.H. Research and Application of Multi-Objective Ant-Genetic Algorithm for Region Water Resources Optimal Allocation. Comput. Knowl. Technol. 2007, 23, 1392-1393+1398. (In Chinese)

42. Liu, B.; Sha, J.X. Application of Improved Artificial Fish Swarm Algorithm in Optimal Allocation of Water Resources. Yellow River 2017, 39, 58-62. (In Chinese)

43. Yan, Z.H.; Sha, J.X.; Liu, B.; Tian, W.; Lu, J.P. An Ameliorative Whale Optimization Algorithm for Multi-Objective Optimal Allocation of Water Resources in Handan, China. Water 2018, 10, 87. [CrossRef]

44. Wolpert, D.H.; Macready, W.G. No free lunch theorems for optimization. IEEE Trans. Evol. Comput. 1997, 1, 67-82. [CrossRef]

45. Mirjalili, S.; Mirjalili, S.M.; Lewis, A. Grey wolf optimizer. Adv. Eng. Softw. 2014, 69, 46-61. [CrossRef] 
46. Kalita, K.; Shinde, D.; Chakraborty, S. Grey wolf optimizer-based design of ventilated brake disc. J. Braz. Soc. Mech. Sci. Eng. 2021, 43, 405. [CrossRef]

47. Zakian, P.; Ordoubadi, B.; Alavi, E. Optimal design of steel pipe rack structures using PSO, GWO, and IGWO algorithms. Adv. Struct. Eng. 2021, 24, 2529-2541. [CrossRef]

48. Diastivena, D.; Wahyuningsih, S.; Satyananda, D. Grey Wolf Optimizer algorithm for solving the multi depot vehicle routing problem and its implementation. J. Phys. Conf. Ser. 2021, 1872, 012001. [CrossRef]

49. Zhang, S.; Zhou, Y.; Li, Z.; Pan, W. Grey wolf optimizer for unmanned combat aerial vehicle path planning. Adv. Eng. Softw. 2016, 99, 121-136. [CrossRef]

50. Zhang, Z.; Hong, W. Application of variational mode decomposition and chaotic grey wolf optimizer with support vector regression for forecasting electric loads. Knowl. Based Syst. 2021, 228, 107297. [CrossRef]

51. Ghalambaz, M.; Jalilzadeh, Y.R.; Davami, A.H. Building energy optimization using grey wolf optimizer (GWO). Case Stud. Therm. Eng. 2021, 27, 101250. [CrossRef]

52. Emary, E.; Zawbaa, H.M.; Grosan, C.; Hassenian, A.E. Feature Subset Selection Approach by Gray-Wolf Optimization. In Afro-European Conference for Industrial Advancement. Advances in Intelligent Systems and Computing; Abraham, A., Krömer, P., Snasel, V., Eds.; Springer: Cham, Switzerland, 2015; p. 334.

53. Kumar, A.; Lekhraj; Singh, S.; Kumar, A. Grey wolf optimizer and other metaheuristic optimization techniques with image processing as their applications: A review. IOP Conf. Ser. Mater. Sci. Eng. 2021, 1136, 012053. [CrossRef]

54. Wang, X.; Li, Z.S.; Kang, H.; Huang, Y.P.; Gai, D. Medical Image Segmentation using PCNN based on Multi-feature Grey Wolf Optimizer Bionic Algorithm. J. Bionic Eng. 2021, 18, 711-720. [CrossRef]

55. Sathiyabhama, B.; Kumar, S.U.; Jayanthi, J.; Sathiya, T.; Ilavarasi, A.K.; Yuvarajan, V.; Gopikrishna, K. A novel feature selection framework based on grey wolf optimizer for mammogram image analysis. Neural Comput. Appl. 2021, 33, 14583-14602. [CrossRef]

56. Niu, W.; Feng, Z.; Liu, S.; Chen, Y.; Xu, Y.; Zhang, J. Multiple Hydropower Reservoirs Operation by Hyperbolic Grey Wolf Optimizer Based on Elitism Selection and Adaptive Mutation. Water Resour. Manag. 2021, 35, 573-591. [CrossRef]

57. Dahmani, S.; Yebdri, D. Hybrid Algorithm of Particle Swarm Optimization and Grey Wolf Optimizer for Reservoir Operation Management. Water Resour. Manag. 2020, 34, 4545-4560. [CrossRef]

58. Mirjalili, S.; Saremi, S.; Mirjalili, S.M.; Coelho, L. Multi-objective grey wolf optimizer: A novel algorithm for multi-criterion optimization. Expert Syst. Appl. 2015, 47, 106-119. [CrossRef]

59. Cui, M.L.; Du, H.W.; Wei, Z.L.; Li, C. Research on improved strategy for multi-objective grey wolf optimizer. Comput. Eng. Appl. 2018, 54, 156-164. (In Chinese)

60. Hebei Provincial Water Resources Department; Hebei Provincial Administration of Quality and Technical Supervision. Hebei Province Water Use Quota; Hebei Provincial Water Resources Department: Shijiazhuang, China, 2016. (In Chinese)

61. Hebei Handan Hydrology and Water Resources Survey Bureau. Assessment of Water Resources in Handan (Third); Hebei Handan Hydrology and Water Resources Survey Bureau: Handan, China, 2019; pp. 71-165. (In Chinese)

62. Hebei University of Engneering. Research Report on Development and Utilization of Reclaimed Water in Handan; Hebei University of Engneering: Handan, China, 2018; pp. 213-219. (In Chinese)

63. Handan Water Resources and Hydropower Survey and Design Institute. The Planning of Handan in the South to North Water Transfer Project (Middle Line) of Hebei Province; Handan Water Resources and Hydropower Survey and Design Institute: Handan, China, 2002; pp. 102-110. (In Chinese)

64. Water Conservancy Bureau of Handan. Allocation and Utilization of Surface Water in Handan; Water Conservancy Bureau of Handan: Handan, China, 2020; pp. 21-22. (In Chinese)

65. Zeng, F.C. Research on Supply-requirement Analysis and Optimized Allocation of Water Resources in Xi'an City. Master's Thesis, Chang'an University, Xi'an, China, May 2008. (In Chinese).

66. Coello, C.A.C.; Pulido, G.T.; Lechuga, M.S. Handling multiple objectives with particle swarm optimization. Evol. Comput. IEEE Trans. 2004, 8, 256-279. [CrossRef]

67. Chen, J.H.; Cheng, G. Application of GWO-projection suit model to water allocation for Yunnan Province. J. China Three Gorges Univ. (Nat. Sci.) 2016, 38, 29-35.

68. Long, W.; Cai, S.H.; Jiao, J.J.; Wu, T.B. An Improved GWO. Acta Electron. Sin. 2019, 47, 171-177.

69. Qifang, L.; Sen, Z.; Zhiming, L.; Yongquan, Z. A novel complex-valued encoding grey wolf optimization algorithm. Algorithms 2015, 9, 4 .

70. Madhiarsan, M.; Deepa, S.N. Long-Term Wind Speed Forecasting using Spiking Neural Network Optimized by Improved Modified Grey Wolf Optimization Algorithm. Int. J. Adv. Res. 2016, 4, 356-368. [CrossRef]

71. Long, W.; Zhao, D.Q.; XU, S.J. Improved grey wolf optimization algorithm for constrained optimization problem. J. Comput. Appl. 2015, 35, 2590-2595. (In Chinese)

72. Saremi, S.; Mirjalili, S.Z.; Mirjalili, S.M. Evolutionary population dynamics and grey wolf optimizer. Neural Comput. Appl. 2015, 26, 1257-1263. [CrossRef]

73. Gholizadeh, S. Optimal design of double layer grids considering nonlinear behaviour by sequential grey wolf algorithm. J. Optim. Civ. Eng. 2015, 5, 511-523.

74. Long, W.; Liang, X.; Cai, S. A modified augmented Lagrangian with improved grey wolf optimization to constrained optimization problems. Neural Comput. Appl. 2016, 28, 421-438. [CrossRef] 
75. Mittal, N.; Singh, U.; Sohi, B.S. Modified Grey Wolf Optimizer for Global Engineering Optimization. Appl. Comput. Intell. Soft. Comput. 2016, 2016, 7950348. [CrossRef]

76. Sha, J.X. Application of Improved NSGA-II in Optimal Allocation of Water Resources in Xingtai City. Water Resour. Power 2018, 36, 21-26. (In Chinese)

77. Sha, J.X.; Liu, B.; Xie, X.M.; Lu, H.Y. Study of water resources optimal allocation based on particle swarm optimization. Water Resour. Power 2012, 30, 35-37+69. (In Chinese)

78. Yan, Z.H.; Liu, B.; Zhang, T.; Sha, J.X.; Nie, H.-J. Study of water resources optimal allocation based on multi-objective particle swarm optimization. Water Resour. Power 2014, 32, 35-37+45. (In Chinese)

79. Qu, G.D.; Lou, Z.H. Application of particle swarm algorithm in the optimal allocation of regional water resources based on immune evolutionary algorithm. J. Shanghai Jiaotong Univ. Sci. 2013, 18, 634-640. [CrossRef]

80. Zhang, L.; Xu, Z.X.; Zhang, Z.G. Rational allocation of water resources based on particle swarm optimization. J. China Hydrol. 2009, 29, 41-45+23. (In Chinese)

81. Chen, X.N.; Duan, Q.C.; Qiu, L.; Huang, Q. Application of large scale system model based on particle swarm optimization to optimal allocation of water resources in irrigation areas. Transact. CSAE 2008, 24, 103-106. (In Chinese) 